\title{
Differential Gene Expression for Glutamic Acid Decarboxylase and Type II Calcium-Calmodulin-dependent Protein Kinase in Basal Ganglia, Thalamus, and Hypothalamus of the Monkey
}

\author{
D. L. Benson, ${ }^{1}$ P. J. Isackson, ${ }^{1,2}$ S. H. C. Hendry, ${ }^{1}$ and E. G. Jones ${ }^{1}$ \\ Departments of ${ }^{1}$ Anatomy and Neurobiology and ${ }^{2}$ Biological Chemistry, University of California, Irvine, California 92717
}

\begin{abstract}
In situ hybridization histochemistry, using cRNA probes, revealed a complementarity in the distributions of cells in the basal ganglia, basal nucleus of Meynert, thalamus, hypothalamus, and rostral part of the midbrain that showed gene expression for glutamic acid decarboxylase (GAD) or the $\alpha$-subunit of type II calcium-calmodulin-dependent protein kinase (CAM II kinase- $\alpha$ ). Cells in certain nuclei such as the thalamic reticular nucleus, globus pallidus, and pars reticulata of the substantia nigra show GAD gene expression only; others in nuclei such as the basal nucleus of Meynert, medial mamillary nuclei, and ventromedial hypothalamic nuclei show CAM II kinase- $\alpha$ gene expression only. A few nuclei, for example, the pars compacta of the substantia nigra and the greater part of the subthalamic nucleus, display gene expression for neither GAD nor CAM II kinase- $\alpha$. In other nuclei, notably those of the dorsal thalamus, and possibly in the striatum, GAD- and CAM II kinase-expressing cells appear to form two separate populations that, in most thalamic nuclei, together account for the total cell population.

In situ hybridization reveals large amounts of CAM II kinase- $\alpha$ mRNA in the neuropil of most nuclei containing CAM II kinase- $\alpha$-positive cells, suggesting its association with dendritic polyribosomes. The message may thus be translated at those sites, close to the synapses with which the protein is associated.
\end{abstract}

The in situ hybridization results, coupled with those from immunocytochemical staining for CAM II kinase- $\alpha$ protein, indicate that CAM II kinase- $\alpha$ is commonly found in certain non-GABAergic afferent fiber systems but is not necessarily present in the postsynaptic cells on which they terminate. It appears to be absent from most GABAergic fiber systems but can be present in the cells on which they terminate. This suggests that the kinase may be differentially engaged in pre- and postsynaptic functions at certain synapses.

Neurons in many centers of the mammalian CNS can be classified into functional groups on the basis of neurotransmitter and/or neuropeptide content (reviewed in, e.g., Emson, 1983).

\footnotetext{
Received Aug. 8, 1990; revised Jan. 4, 1991; accepted Jan. 9, 1991.

This work was supported by Grants NS22317, NS21377, NS24747, and EY07193 from NIH, U.S. Public Health Service. We thank Dr. M. B. Kennedy for providing the antibody to CAM II kinase.

Correspondence should be addressed to Dr. E. G. Jones, University of California at Irvine, Department of Anatomy and Neurobiology, Irvine, CA 92717.

Copyright $\odot 1991$ Society for Neuroscience $0270-6474 / 91 / 111540-25 \$ 03.00 / 0$
}

Immunocytochemical studies that provided the early insights into such classifications have now been complemented by studies in which mRNAs for neurotransmitter-related enzymes, for receptors, or for the precursors of various neuropeptides have been localized to particular neurons by the method of in situ hybridization of radiolabeled cDNA or cRNA probes (e.g., Wuenschell et al., 1986; Young et al., 1986; Chesselet et al., 1987; Gerfen and Young, 1988; Benson et al., 1989, 1991a; Chesselet and Robbins, 1989; Seroogy et al., 1989; Wada et al., 1989).

Other molecules that have been revealed by immunocytochemistry as useful markers of neuronal identity in the CNS include surface proteoglycans (Hockfield and McKay, 1983; Arimatsu et al., 1987; Hendry et al., 1988), calcium-binding proteins (e.g., Celio and Heizmann, 1981; Cowan et al., 1987; Hendry et al., 1989), and various second-messenger-related proteins such as protein kinases and their substrates (Nestler and Greengard, 1984; Nestler et al., 1984). Some of the latter, for example, synapsin I (De Camilli et al., 1983; Walaas et al., 1988), may be distributed in virtually all neurons; others such as type II calcium-calmodulin-dependent protein kinase and protein kinase $\mathrm{C}$ appear to have a more restricted regional distribution (Erondu and Kennedy, 1985; Ouimet et al., 1984a; Worley et al., 1986a,b), and some, for example, the cAMP-and dopamineregulated phosphoproteins DARPP-32 and ARPP-21, are localized in specific neuronal populations (Ouimet et al., 1984b, 1989). In certain neurons, the presence of particular phosphoproteins may be correlated with the coexistence of a particular type of synapse. DARPP-32 and ARPP-21, for example, are found primarily in neurons expressing $D_{1}$ dopamine receptors.

By making probes for specific mRNAs, it is now possible to detcrminc if ncurons that express the gene for a particular transmitter-synthesizing enzyme or for a neuroactive peptide are also expressing a particular second-messenger-related phosphoprotein. In the present study, we have examined populations of neurons that express the genes for glutamic acid decarboxylase (GAD), the enzyme involved in synthesis of one of the major transmitters of the forebrain, GABA (Roberts et al., 1976) and for the $\alpha$-subunit of type II calcium-calmodulin-dependent protein kinase (CAM II kinase- $\alpha$ ), one of the most common forebrain kinases (Bennett et al., 1983; Ouimet et al., 1984a). GAD was anticipated to be expressed in a particular set of neurons, while CAM II kinase was expected, from all past work, to be found in virtually all forebrain neurons. By preparing specific riboprobes for use in in situ hybridization studies, it has been possible to indicate that these genes are, in fact, expressed in different neuronal populations. 


\section{Materials and Methods}

Preparation of $c R N A$ probes. The generation of GAD and CAM II kinase- $\alpha$ cDNAs from mRNA of monkey cerebral cortex and the preparation of cRNA probes from them have been described in detail elsewhere (Benson et al., 1991a).

Antisense and sense GAD riboprobes were transcribed from a 365nucleotide monkey GAD cDNA encoding a portion of the $67-\mathrm{kDa}$ (Kaufman et al., 1989) form of GAD. Antisense and sense CAM II kinase- $\alpha$ riboprobes were transcribed from a 375-nucleotide monkey cDNA encoding a part of CAM II kinase- $\alpha$. This cDNA is $95 \%$ identical to published rat CAM II kinase- $\alpha$ cDNA and extends from nucleotide 868 to nucleotide 1184 (Lin et al., 1987; see also Bulleit et al., 1988) with the addition of a 33-nucleotide insert beginning at nucleotide 985 . Antisense riboprobes made from this cDNA recognize both CAM II kinase- $\alpha$ and $\alpha-33$ mRNAs, but do not recognize the mRNA encoding CAM II kinase- $\beta$ (Benson et al., 1991a,b). All probes were labeled with $\alpha-{ }^{35}$ S-UTP for in situ hybridization studies.

In situ hybridization. The study was carried out on the brains of four adult macaque monkeys (two Macaca fuscata and two Macaca fascicularis). Three of the monkeys had been subjected to monocular visual deprivation for 2-15 d as part of another study (Benson et al., 1991a) but were otherwise normal. The fourth monkey was normal. No differences were detected between monkeys in the regions examined. The animals were given an overdose of Nembutal and perfused through the ascending aorta with 1-3 liters of $4 \%$ paraformaldehyde in $0.05 \mathrm{M}$ phosphate buffer at $\mathrm{pH} 7.4$. Brains were postfixed overnight in $4 \%$ paraformaldehyde and then infiltrated with $20 \%$ sucrose in $4 \%$ paraformaldehyde.

Blocks containing the striatum (caudate nucleus, nucleus accumbens, and putamen), diencephalon, and upper part of the midbrain were frozen on dry ice, and $25-\mu \mathrm{m}$ serial sections were cut on a sliding microtome in the frontal plane. Sections were collected in groups of five in cold 0.1 M phosphate buffer. One section of each group was labeled with the antisense GAD probe, a second was labeled with the antisense CAM II kinase probe (see below), and a third was stained with $0.25 \%$ thionin. The remaining two were used for repeat series and for sense controls.

Free-floating sections were washed in $0.1 \mathrm{M}$ glycine in $0.1 \mathrm{M}$ phosphate buffer $(\mathrm{pH}, 7.2)$ and pretreated with proteinase $\mathrm{K}(1 \mu \mathrm{g} / \mathrm{ml}$ in $0.1 \mathrm{M}$ Tris buffer at $\mathrm{pH} 8$ ) for $30 \mathrm{~min}$ at $30^{\circ} \mathrm{C}$; this was followed by $0.25 \%$ acetic anhydride in $0.1 \mathrm{~m}$ triethanolamine $(\mathrm{pH}, 8.0)$ and washing in twicestrength saline, sodium citrate $(2 \times \mathrm{SSC})$ at room temperature. Sections were then incubated in a prehybridization solution containing 50\% deionized formamide, $10 \%$ dextran sulfate, $0.7 \%$ Ficoll, $0.7 \%$ polyvinyl pyrolidone, $350 \mathrm{mg} / \mathrm{ml} \mathrm{BSA}, 0.15 \mathrm{mg} / \mathrm{ml}$ yeast $t$ RNA, $0.33 \mathrm{mg} / \mathrm{ml}$ denatured herring sperm DNA, and $20 \mathrm{~mm}$ dithiothreitol (DTT) for 1 $\mathrm{hr}$ at $60^{\circ} \mathrm{C}$. Finally, they were transferred to fresh prehybridization buffer containing an additional $20 \mathrm{~mm}$ DTT and $1 \times 10^{4} \mathrm{cpm} / \mu \mathrm{l}$ of the $\alpha-{ }^{35} \mathrm{~S}$ antisense riboprobe for a minimum of $20 \mathrm{hr}$ at $60^{\circ} \mathrm{C}$ (Gall and Isackson, 1989).

Following hybridization, sections were washed in $4 \times$ SSC, digested with ribonuclease $\mathrm{A}$, then washed through descending concentrations of SSC with $5 \mathrm{~mm}$ DTT to a final stringency of $0.1 \times \mathrm{SSC}, 60^{\circ} \mathrm{C}$, for $1 \mathrm{hr}$. Sections were mounted onto gelatin-coated slides, dried, and exposed to Amersham $\beta$-max film for $1-4 \mathrm{~d}$. After development of the film autoradiograph, the sections were lipid extracted in chloroform, dipped in Kodak NTB2 emulsion diluted 1:1 with water, exposed for $7-15 \mathrm{~d}$ at $4^{\circ} \mathrm{C}$, developed in Kodak D19, fixed, and stained through the emulsion with cresyl violet.

Sense-strand probes were hybridized to selected sections as controls. In all control sections, there was no labeling above a low background level (Fig. 1). The GAD and CAM II kinase- $\alpha$ antisense riboprobes also served as controls for one another because they possess similar $G / C$ ratios.

Camera lucida drawings at low magnification $(20 \times)$ were made of the outlines of the hybridized sections, and major landmarks such as fiber tracts and blood vessels were traced on them. Then, by switching to dark-field illumination, the distribution of labeled neurons was plotted, and the density of neuronal and neuropil labeling was indicated, using previously agreed criteria, as shown in Figure 2. Adjacent GADand CAM II kinase- $\alpha$-hybridized sections were drawn. Thereafter, the other adjacent, thionin-stained section was drawn at the same magnification to show the borders of nuclei and other cell groupings, and using the profiles of the same sectioned blood vessels as guides, the drawings were superimposed. Nuclei are named according to Emmers and Akert (1963) and Jones (1985). Sizes of grain accumulations over labeled cells
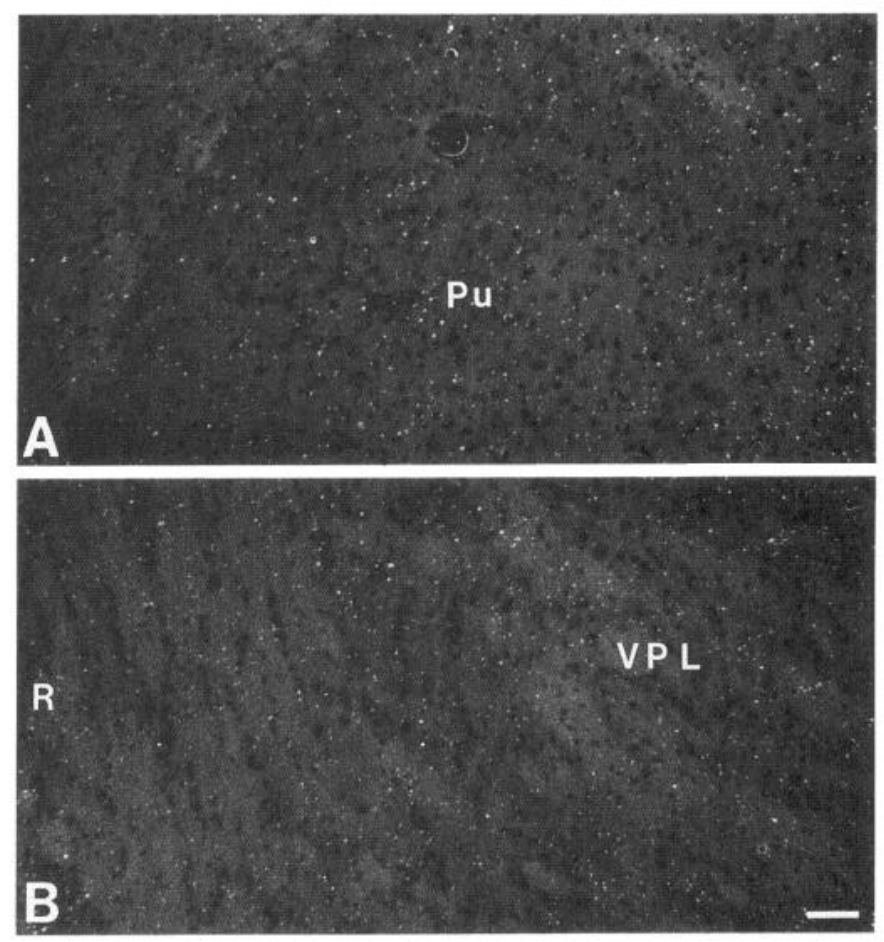

Figure 1. Dark-field autoradiographs showing only background labeling when sections were hybridized with CAM II kinase- $\alpha(A)$ and GAD $(B)$ sense probes. $P u$, putamen; $R$, reticular nucleus; $V P L$, ventral posterior lateral nucleus of the thalamus. Scale bar, $25 \mu \mathrm{m}$.

and sizes of cells with identifiable nuclei in thionin-stained sections adjacent to the autoradiographic sections were measured at a magnification of $400 \times$ using an eyepiece reticule, and an approximation of the numerical density of labeled cells was obtained by counting the number of labeled or thionin-stained neurons falling within an area of either $600 \times 600 \mu \mathrm{m}$ or in a strip $500 \mu \mathrm{m}$ wide across linear nuclei and laminae, as defined by the eyepiece reticule.

Immunocytochemistry. Serial sections of the basal ganglia, thalamus, and brainstem of six normal $M$. fascicularis monkeys, stained immunocytochemically for GABA and prepared as part of another study (Hunt et al., 1991), were available for comparison. Further sections from these monkeys, all of which had been perfused with $2 \%$ paraformaldehyde and $0.1 \%$ or $0.2 \%$ glutaraldehyde in $0.1 \mathrm{M}$ phosphate buffer, were stained immunocytochemically for CAM II kinase- $\alpha$ as follows:

Frozen sections 15 or $20 \mu \mathrm{m}$ thick and cut in the frontal plane were washed thoroughly in $0.1 \mathrm{M}$ phosphate buffer and treated for $2 \mathrm{hr}$ at $4^{\circ} \mathrm{C}$ in $5 \%$ normal rabbit serum in phosphate buffer containing $3 \%$ Triton $\mathrm{X}-100$. They were then incubated for $18-24 \mathrm{hr}$ at $4^{\circ} \mathrm{C}$ in a $1: 250$ solution of mouse ascites fluid containing a previously characterized mouse monoclonal antibody that recognizes the $\alpha$-subunit of rat CAM II kinase- $\alpha$ (Erondu and Kennedy, 1985). After washing well, they were treated for $2 \mathrm{hr}$ with horseradish peroxidase-conjugated rabbit antimouse immunoglobulins (DAKO) followed by washing and development of a horseradish peroxidase reaction product with $0.02 \% 3,3^{\prime}$ diaminobenzidine tetrahydrochloride and $0.001 \%$ hydrogen peroxide. Sections were dehydrated, cleared, and mounted. Adjacent sections were stained with $0.25 \%$ thionin. Control staining, using ascites fluid from a non-immunoglobulin-secreting mouse tumor instead of the primary antibody, revealed no specific staining.

\section{Results}

\section{Patterns of in situ hybridization}

Two major features distinguish the labeling of neurons by the CAM II kinase- $\alpha$ or GAD riboprobes: a far greater degree of associated neuropil labeling with the CAM II kinase- $\alpha$ probe and a strong tendency toward complementarity in the distribution of neurons labeled by the two probes (Fig. 2). 

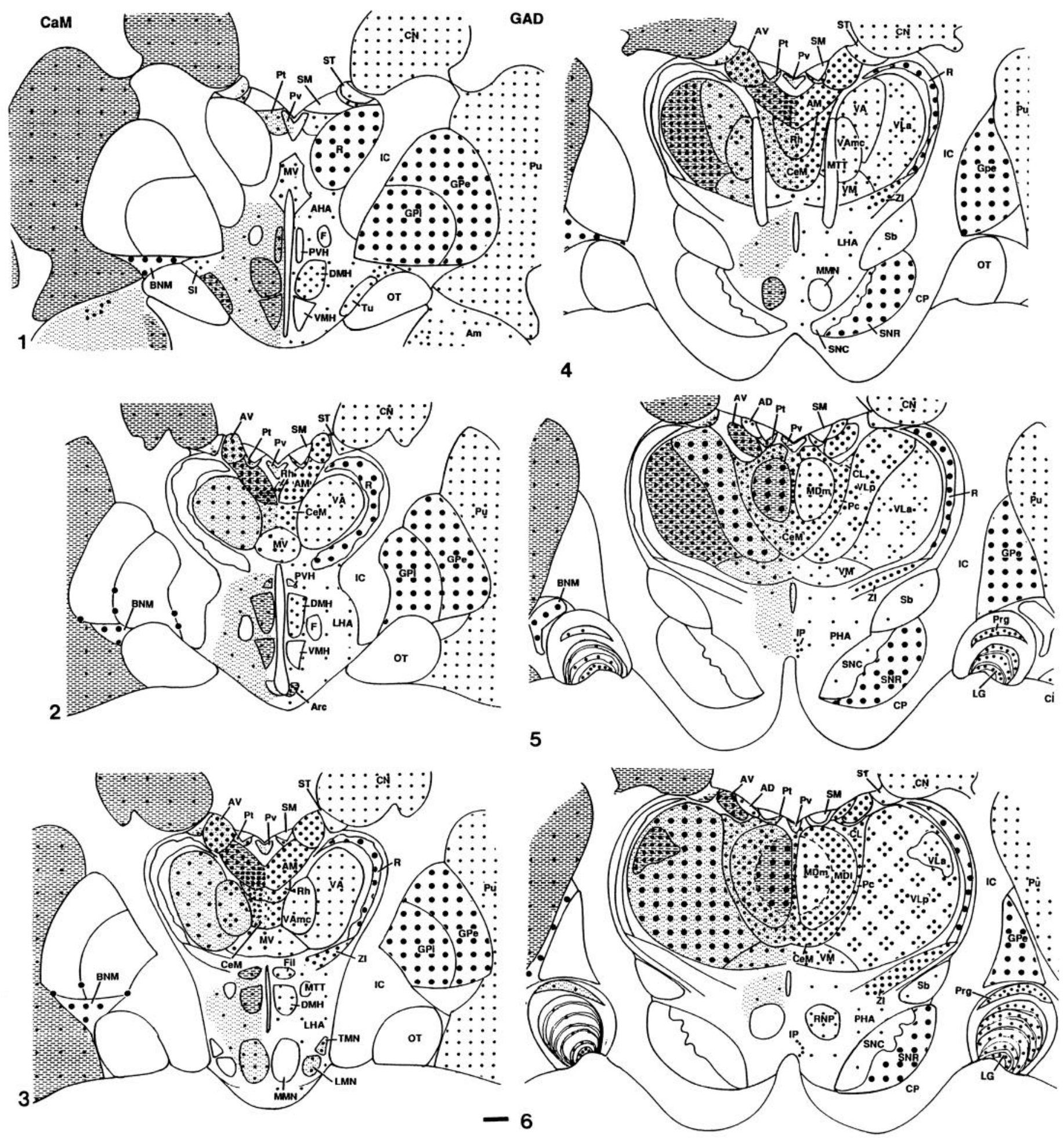

Figure 2. Camera lucida drawings of the outlines of nuclei in the basal ganglia, diencephalon, and midbrain seen in thionin-stained frontal sections from a monkey brain. The left side in $1-10$ shows distribution and density of CAM II kinase- $\alpha(\mathrm{CaM})$ probe hybridization, and right side, those of GAD probe hybridization. For other abbreviations, see Appendix. Scale bar, $1 \mathrm{~mm}$. In this and all subsequent photomicrographs, CAM II kinase$\alpha$ preparations are shown as though from the left side of the brain, and GAD preparations, as though from the right side.

$G A D$. Whenever GABA neurons are localized by hybridization of the GAD riboprobes (Fig. 3), the autoradiographic labeling is densely concentrated over the cell somata and gives a clear indication of the presence of individual cells (Figs. 4-7), though because of the RNAse treatment, only the nuclei of the cells are clearly visible (Fig. 3). Populations of large, medium, and small GABA cells, known from immunocytochemical studies and visible in the sections from Hunt et al. (1991), are rendered clearly visible by the sizes of the grain concentrations overlying each soma. For example, the large neurons of the 


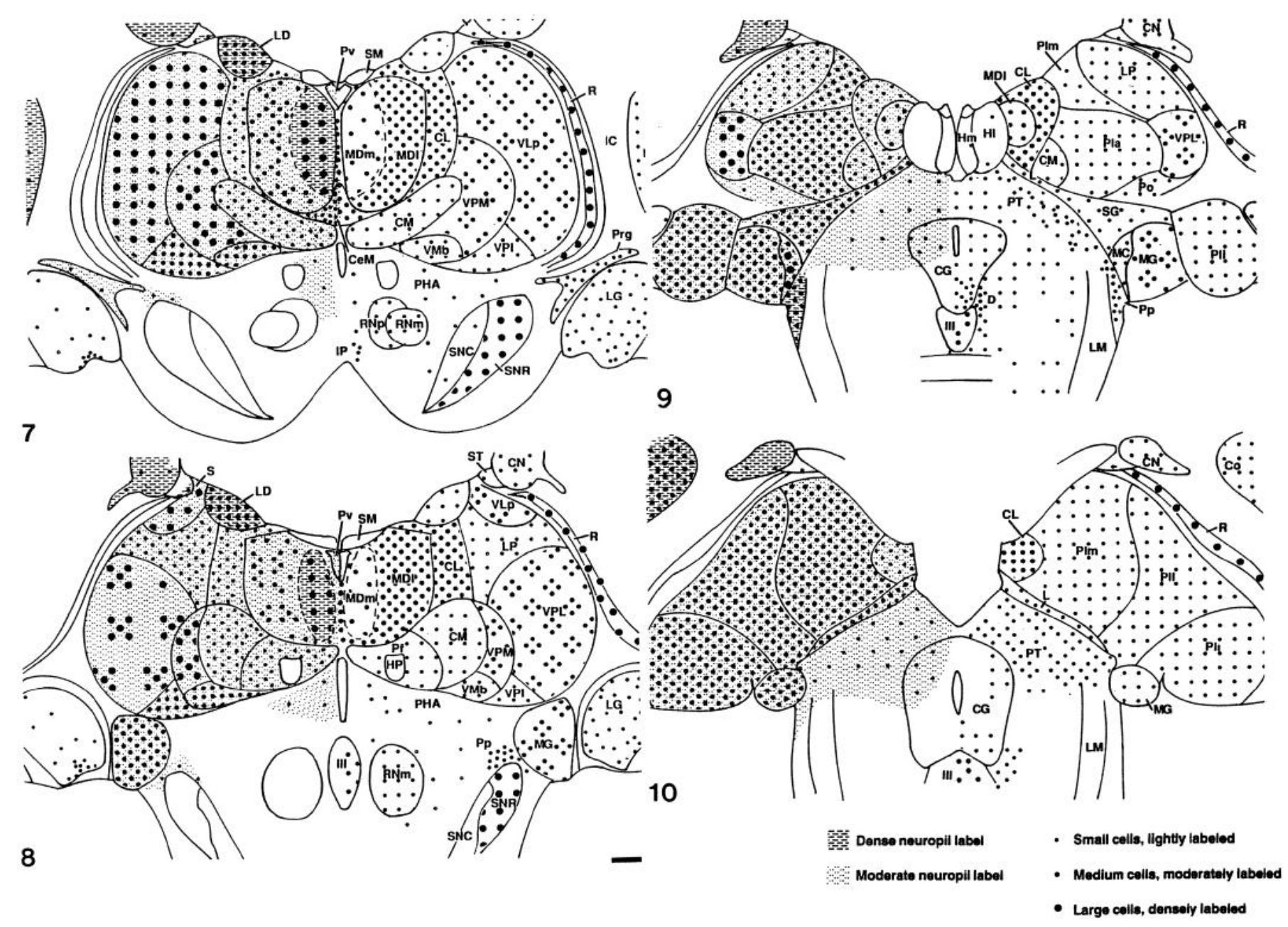

Figure 2. Continued.

reticular nucleus or globus pallidus, measuring $20-35 \mu \mathrm{m}$ in somal diameter in the adjoining thionin-stained sections or in GABA-immunoreactive preparations, can be correlated with grain clusters measuring 25-50 $\mu \mathrm{m}$ (Table 1). Grain clusters measuring $12-18 \mu \mathrm{m}$ in diameter in the striatum correlate with GABA-immunoreactive somata measuring 10-15 $\mu \mathrm{m}$, and the smallest grain clusters measuring $10-12 \mu \mathrm{m}$ in diameter correlate with the smallest GABA-immunoreactive neurons of certain thalamic and hypothalamic nuclei, such as the centre médian and tuberal, where they measure $8-10 \mu \mathrm{m}$ in diameter.

Apart from the arcuate nucleus of the hypothalamus, which shows such dense hybridization of the probe (Fig. 5) that the individual small, labeled somata are difficult to detect, neuropil labeling with the GAD riboprobe is minimal or absent in basal ganglia, thalamus, hypothalamus, and midbrain (Fig. 3).

$C A M$. The pattern of CAM II kinase- $\alpha$ in situ hybridization is quite different. Virtually all nuclei that contain labeled cells show significant labeling of the neuropil as well as of cell somata (Figs. 2-10). In certain nuclei such as those of the striatum and certain of those in the hypothalamus, individual labeled somata are difficult to isolate on account of dense overall labeling and because there is little difference in density between somal and neuropil labeling (Figs. 4,8). The only nucleus in which probe hybridization over the neuropil is virtually absent is the basal nucleus of Meynert, in which individual, heavily labeled large cells are usually separated from one another by some distance (Fig. 8). The grain clusters, measuring $30-45 \mu \mathrm{m}$ in diameter, reflect the size of the underlying cells of the basal nucleus, which are $20-35 \mu \mathrm{m}$ in diameter in the adjacent thionin-stained and CAM-immunoreactive sections (Table 1). The nuclei showing the densest neuropil labeling are the caudate nucleus, nucleus accumbens, and putamen, followed by the anterior ventral lateral nucleus of the thalamus and the ventral medial, tuberal, and medial mamillary nuclei of the hypothalamus. In these, the labeling is so dense and homogeneous that grain clusters indicating hybridization of the probe to cell somata are detected only by close observation (Figs. 4, 6, 8). When identified, these clusters measure $12-18 \mu \mathrm{m}$ in diameter (Fig. 3). Even denser labeling is observed in the claustrum and cerebral cortex (Figs. $2,5,7)$. In most parts of the hypothalamus and in the pretectum, where there is also a diffuse labeling of the neuropil (Figs. 11, 12), the overall grain density is relatively less than in the nuclei of the striatum, but clusters of grains indicative of cell somal labeling are also difficult to define. When isolated, these are also small and measure $12-15 \mu \mathrm{m}$ in diameter.

In all other CAM II kinase- $\alpha$-positive nuclei (Figs. 2, 4, 10), neuropil labeling varies from light-to-moderate to dense, but somal labeling is usually relatively more intense, and the individual cells can be identified. The diameters of grain clusters over individual cells reflect the sizes of the major population of 
cells in the underlying nucleus (Fig. 3), as determined from the adjacent thionin-stained sections (Table 1), and correlate with the sizes of cells immunoreactive for CAM II kinase- $\alpha$ in the immunocytochemically stained sections (Figs. 11-13). The basal nucleus of Meynert (Fig. 8) contains the largest grain clusters, followed by the ventral lateral posterior and ventral posterior lateral nuclei of the thalamus, where they measure $30-40 \mu \mathrm{m}$, correlating with large thionin-stained or CAM II kinase- $\alpha$-immunoreactive somata that measure $20-35 \mu \mathrm{m}$ in these nuclei. Medium-sized grain clusters measuring $18-20 \mu \mathrm{m}$ in thalamic nuclei such as the anteroventral and those of the pulvinar (anterior, inferior, lateral, and medial) correlate with thionin- and immunocytochemically stained cells measuring $15-18 \mu \mathrm{m}$ in those nuclei. Small grain clusters measuring $12-15 \mu \mathrm{m}$ in the centre médian nuclcus correlate with stained somata measuring $10-12 \mu \mathrm{m}$.

In general, in the thalamus, where cells are largest, the grain density overlying their somata is greatest and neuropil labeling heaviest. Where cells are smallest, somal labeling is lowest and neuropil labeling weakest. This contrast is especially evident when comparing the labeling of the ventral nuclei with those of the intralaminar system or the labeling of the medial, magnocellular, and lateral mixed-cell divisions of the mediodorsal nucleus (Figs. 6, 7).

\section{Complementarity}

The complementarity in the distributions of neuronal populations revealed by hybridization of GAD or CAM II kinase- $\alpha$ riboprobes (Fig. 2) is especially evident in nuclei such as the reticular nucleus of the thalamus, zona incerta, parts of the lateral geniculate nuclcus, globus pallidus, basal nucleus of Meynert, habenular nuclei, substantia nigra, red nucleus, and certain nuclei of the hypothalamus. In these nuclei, cells clearly show hybridization of one probe and not of the other. Cells of the thalamic reticular nucleus, zona incerta, red nucleus, substantia nigra, globus pallidus (both segments), habenular nuclei, and lateral hypothalamic area show hybridization of the GAD riboprobe but nol of the CAM II kinase- $\alpha$ riboprobe. Cells of the basal nucleus of Meynert and of the ventral medial and medial mamillary nuclei of the hypothalamus show hybridization of CAM II kinase- $\alpha$ but not of GAD riboprobes. In the dorsal lateral geniculate nucleus, cells in the $S$ layers and interlaminar zones show CAM II kinase- $\alpha$ but little GAD riboprobe hybridization, while those in the principal laminae (1-6) show GAD but not CAM II kinase- $\alpha$ riboprobe hybridization (Fig. 9). Patterns in other nuclei not mentioned here can be seen in Figure 2 and in Table 1.

In nuclei in which cells show both GAD and CAM II kinase- $\alpha$ hybridization, the populations of cells showing GAD or CAM II kinase- $\alpha$ probe hybridization in a single nucleus commonly vary in size (Table 1). This is especially evident throughout the principal relay nuclei of the dorsal thalamus in which somata showing GAD probe hybridization are consistently smaller than those showing CAM II kinase- $\alpha$ probe hybridization (Figs. 4 7 , Table 1). This difference is not clear in the intralaminar nuclei of the thalamus, the striatum, pretectal nuclei, or hypothalamus, in which labeled cells are similar in size (Fig. 3, Table 1).

Nuclei consistently showing no hybridization of either the GAD or the CAM II kinase- $\alpha$ riboprobes are rare. Among these, the pars compacta of the substantia nigra and the subthalamic nucleus stand out. No CAM II kinase- $\alpha$ probe hybridization was revealed in either; GAD probe hybridization revealed la- beled cells only around the dorsomedial margin of the pars compacta and only in very small numbers in the subthalamic nucleus, not in every section through the nucleus (Fig. 10). The paraventricular nuclei of the epithalamus showed no obvious somal labeling for either probe, but weak CAM II kinase- $\alpha$ hybridization signal was detected over the neuropil.

Detailed neuron counts were not made of every nucleus, but a large number were sampled (Table 1). In certain nuclei, neurons labeled with either the GAD or the CAM II kinase- $\alpha$ riboprobes or collectively by the two riboprobes appear to account for the total population of neurons (Table 1). In the reticular nucleus of the thalamus, direct examination of counterstained, autoradiographic sections reveals no neurons unlabeled for GAD mRNA. Similarly, counts of cells in thionin-stained sections adjacent to the autoradiographs and not subjected to RNAse treatment reveal the same density of neurons as those labeled in the autoradiographs (on average, 31 per $360,000-\mu \mathrm{m}^{2}$ field). In the ventral posterior nucleus of the thalamus, 19-31 GAD riboprobe-hybridized and 73-77 CAM II kinase- $\alpha$ riboprobehybridized cells were counted in $600-\mu \mathrm{m} \times 600-\mu \mathrm{m}$ squares. Squares of this size in the thionin-stained sections that were of the same thickness contained 96-111 identifiable neurons. In the central lateral nucleus of the thalamus, $500-\mu \mathrm{m}$-wide traverses across the width of this intralaminar nucleus containcd 31-35 GAD probe-hybridized cells, 87-93 CAM II kinase- $\alpha$ probe-hybridized cells, and 70-120 thionin-stained cells. Some thalamic nuclei showed subdivisions in which the complementarity was especially evident. In the mediodorsal nucleus, in particular, the medial and lateral divisions showed differential distributions reflecting the differences in overall cell density.

In the caudate nucleus and putamen, by contrast, the GAD probe and identifiable CAM II kinase- $\alpha$ probe-hybridized populations would not account for the total neuronal population; $600-\mu \mathrm{m} \times 600-\mu \mathrm{m}$ squares in these nuclei contained $20-26$ GAD mRNA-positive cells, 4-10 CAM II kinase- $\alpha$ mRNApositive cells, and 176-196 thionin-stained cells. It is important to note, however, that CAM II kinase- $\alpha$ mRNA-positive cell somata are difficult to detect in the autoradiographs (see above, Figs. 3, 8).

\section{Immunoreactivity for GABA and CAM II kinase- $\alpha$}

$G A B A$. The distributions of GABA- and/or GAD-immunoreactive cells in the thalamus, basal ganglia, and certain other regions of the monkey examined in the present study have been described elsewhere (Smith et al., 1987a,b; Hunt et al., 1991). Quantitative data have also been reported for a number of thalamic nuclei in monkeys (Montero and Zempel, 1986; Hendry, 1991; Hunt et al., 1991). No data are available on GABA- or GAD-immunoreactive cells in the monkey hypothalamus. The distributions and percentages of GABA-immunoreactive neurons in nuclei for which data are available are very similar to those obtained by counting GAD-probe-hybridized cells in the present study (see Discussion).

CAM II kinase. CAM II kinase- $\alpha$ immunoreactivity has not been comprehensively described for the nuclei of the monkey investigated here. The pattern of distribution of immunoreactive cells in preparations prepared as part of the present study is similar to that seen for cells showing hybridization of the CAM II kinase- $\alpha$ probe. There are, however, large regions of neuropil and fiber immunoreactivity that do not contain immunoreactive cells or cells labeled by in situ hybridization (Figs. $9,11-13)$. 


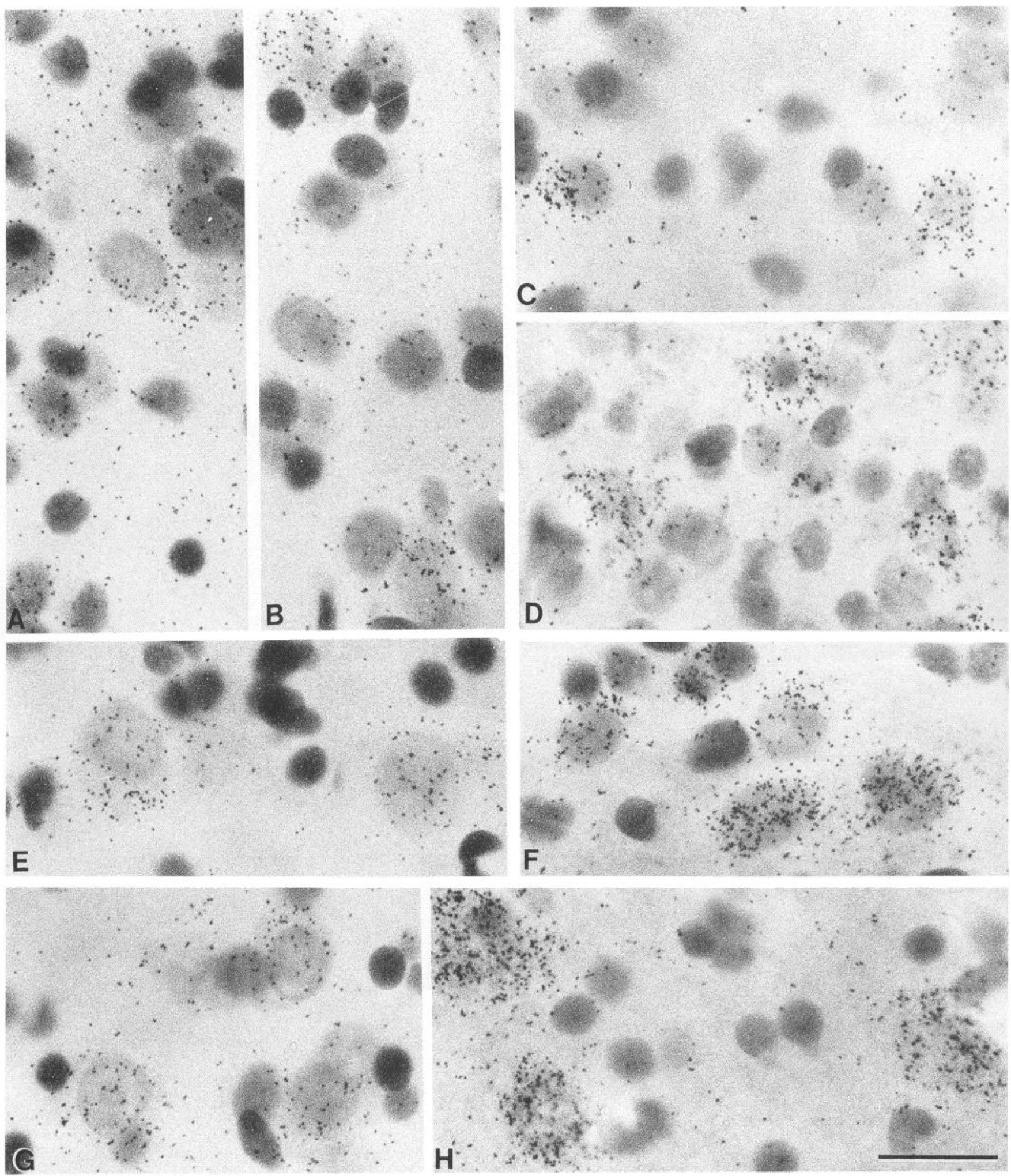

Figure 3. Bright-field photomicrographs, at same magnification, from autoradiographs showing hybridization of CAM II kinase- $\alpha(A, B$, $E$, $G$ ) and GAD $(C, D, F, H)$ riboprobes. $A$ and $B$ show substantial CAM II kinase- $\alpha$ neuropil labeling in the tuberal nucleus $(A)$ and putamen $(B)$, while $E$ and $G$ show labeling more obviously located over cells in the posterior ventral lateral $(E)$ and anteromedial $(G)$ thalamic nuclei. GAD labeling is more obviously located over cells in the preparations from the putamen $(C)$, dorsal lateral geniculate nucleus, lamina $4(D)$, reticular nucleus $(F)$, and substantia nigra pars reticulata $(H)$. Note different dimensions of grain clusters interpreted as indicative of differences in size of underlying cells. Only cell nuclei are visible because of RNAse treatment. Darkly stained, unlabeled nuclei are those of neuroglial cells. Scale bar, $25 \mu \mathrm{m}$. 

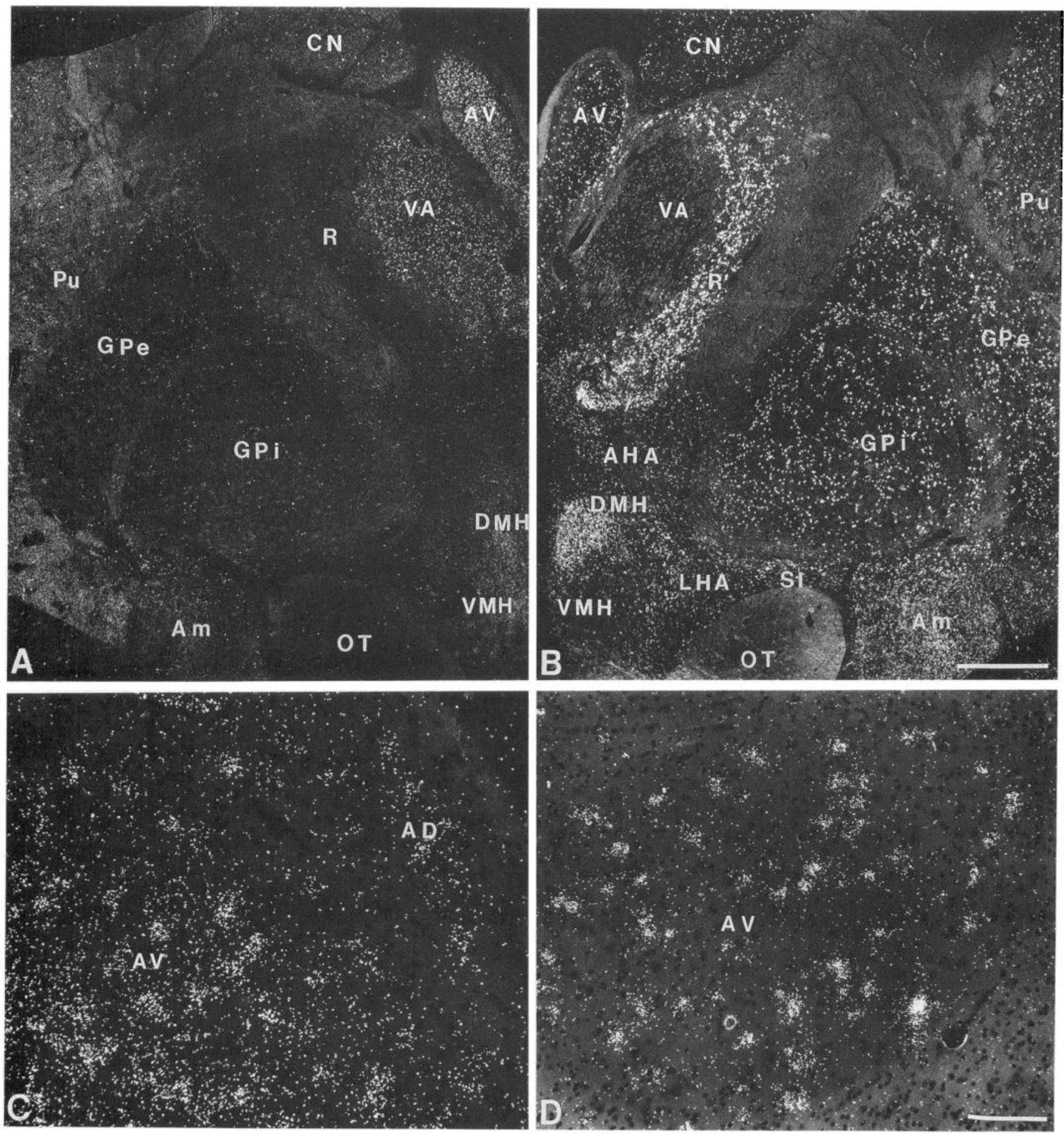

Figure 4. $A$ and $B$, Closely adjacent frontal sections through the anterior part of the thalamus and adjacent parts of the basal ganglia showing the distributions of CAM II kinase- $\alpha-(A)$ and GAD- $(B)$ expressing cells. Note dense neuropil labeling of putamen $(P u)$ in $A$, lack of CAM II kinase- $\alpha$ probe hybridization in the globus pallidus $(G P e, G P i)$ and reticular nucleus $(R)$, and lack of GAD probe hybridization in the ventral medial hypothalamic nucleus $(V M H)$. Scale bar, $2 \mathrm{~mm}$. $C$ and $D$, Hybridization of the CAM II kinase- $\alpha$ probe $(C)$ to neuropil and putatively larger somata in the anteroventral $(A V)$ and anterodorsal $(A D)$ thalamic nuclei and hybridization of the GAD probe to smaller somata in the anteroventral nucleus (D). Scale bar, $50 \mu \mathrm{m}$. For other abbreviations, see Appendix.

\section{Fiber tracts}

The stria terminalis, the fornix, the striatonigral bundles that traverse the cerebral peduncle, and the stratum zonale of the thalamus show very dense immunoreactive staining for CAM II kinase- $\alpha$ (Figs. 11-13). Weaker staining of smaller numbers of fibers is seen in the internal capsule, internal and external medullary laminae of the thalamus, and the cerebral peduncle. No staining is seen in the stria medullaris, mamillothalamic tract, 
Table 1. Relative numbers of neurons showing hybridization of cRNA probes for GAD or CAM II kinase- $\alpha$ in selected nuclei of thalamus and basal ganglia

\begin{tabular}{|c|c|c|c|c|c|c|}
\hline \multirow[b]{2}{*}{ Nucleus } & \multicolumn{2}{|l|}{ GAD cells } & \multicolumn{2}{|c|}{ CAM II kinase cells } & \multicolumn{2}{|c|}{ Thionin-stained cells } \\
\hline & Number & Diameter $(\mu \mathrm{m})$ & Number & Diameter $(\mu \mathrm{m})$ & Number & Diameter $(\mu \mathrm{m})$ \\
\hline \multicolumn{7}{|l|}{ Thalamic nuclei } \\
\hline $\mathrm{R}$ & $29-35(31)$ & $25-50(37)$ & 0 & - & $26-37(31)$ & $20-35(32)$ \\
\hline $\mathrm{ZI}$ & $37-68(52)$ & $20-25(22)$ & 0 & - & $49-57(54)$ & $10-15(12)$ \\
\hline AV & $27-31(29)$ & $15-18(17)$ & $57-60(59)$ & $25-35(30)$ & $99-104(101)$ & $15-20(19)$ \\
\hline AM & $35-43(39)$ & $15-20(17)$ & $75-80(75)$ & $25-40(32)$ & $92-110(101)$ & $12-18(17)$ \\
\hline $\mathrm{AD}$ & $12-14(13)$ & $20-25(23)$ & $20-25(22)$ & $25-30(27)$ & $31-39(35)$ & $25-30(27)$ \\
\hline LD & $39-47(44)$ & $15-18(17)$ & $55-61(59)$ & $30-45(40)$ & $93-110(101)$ & $10-15(12)$ \\
\hline MV & $21-27(24)$ & $20-25(23)$ & $57-63(60)$ & $18-30(27)$ & $77-85(81)$ & $14-21(18)$ \\
\hline $\mathrm{Rh}$ & $25-29(27)$ & $15-17(16)$ & $60-65(62)$ & $30-40(35)$ & $74-82(79)$ & $14-18(16)$ \\
\hline $\mathrm{CeM}$ & $37-41(39)$ & $25-30(27)$ & $61-66(63)$ & $27-35(32)$ & $110-121(117)$ & $20-25(23)$ \\
\hline $\mathrm{CL}$ & $31-35(32)$ & $20-30(25)$ & $67-93(81)$ & $38-42(40)$ & $70-120(105)$ & $16-25(21)$ \\
\hline $\mathrm{Pc}$ & $35-39(36)$ & $25-30(27)$ & $38-96(71)$ & $35-45(40)$ & $69-137(96)$ & $20-34(29)$ \\
\hline $\mathrm{CM}$ & $38-42(41)$ & $10-12(11)$ & $99-113(108)$ & $25-35(30)$ & $128-132(129)$ & $10-18(16)$ \\
\hline Pf & $32-36(33)$ & $15-18(17)$ & $89-102(97)$ & $25-35(32)$ & $92-106(101)$ & $12-20(18)$ \\
\hline $\mathrm{MDm}$ & $25-31(29)$ & $25-35(30)$ & $61-67(65)$ & $35-42(37)$ & $80-84(82)$ & $20-25(24)$ \\
\hline $\mathrm{MDI}$ & $70-74(72)$ & $20-25(22)$ & $86-90(89)$ & $25-35(30)$ & $122-144(136)$ & $12-19(17)$ \\
\hline VA & $19-23(20)$ & $20-25(22)$ & $47-52(49)$ & $35-40(37)$ & $60-64(61)$ & $15-25(20)$ \\
\hline VAmc & $17-21(19)$ & $25-30(27)$ & $43-49(47)$ & $40-50(45)$ & $52-67(62)$ & $29-33(30)$ \\
\hline VLa & $33-37(35)$ & $25-30(27)$ & \multicolumn{2}{|c|}{ labeling too dense to count } & $73-91(85)$ & $19-27(25)$ \\
\hline VLp & $17-21(19)$ & $25-32(30)$ & $44-48(46)$ & $45-50(47)$ & $53-62(58)$ & $20-40(37)$ \\
\hline VPL & $29-31(30)$ & $20-25(23)$ & $73-77(76)$ & $30-40(38)$ & $96-111(101)$ & $15-35(25)$ \\
\hline VPM & $43-49(46)$ & $20-25(23)$ & $89-97(94)$ & $28-38(35)$ & $124-140(134)$ & $20-30(28)$ \\
\hline VMb & $31-35(33)$ & $18-20(91)$ & $42-49(46)$ & $25-40(32)$ & $56-75(65)$ & $18-32(28)$ \\
\hline VPI & $30-34(31)$ & $18-20(19)$ & $48-58(53)$ & $20-30(25)$ & $68-81(76)$ & $15-18(17)$ \\
\hline LP & $45-47(44)$ & $15-20(17)$ & $89-102(97)$ & $22-30(28)$ & $130-143(134)$ & $20-30(28)$ \\
\hline PLa & $41-52(48)$ & $20-25(23)$ & $93-111(100)$ & $25-35(30)$ & $118-162(142)$ & $16-21(19)$ \\
\hline Pli & $44-47(46)$ & $20-27(25)$ & $99-127(113)$ & $25-35(30)$ & $132-158(145)$ & $25-35(33)$ \\
\hline Pll & $39-52(46)$ & $18-20(19)$ & $71-123(97)$ & $25-38(32)$ & $113-168(134)$ & $18-30(25)$ \\
\hline PIm & $41-57(51)$ & $18-22(20)$ & $79-115(98)$ & $25-35(30)$ & $140-151(145)$ & $16-22(20)$ \\
\hline SG-L & $33-41(38)$ & $25-30(27)$ & $48-52(50)$ & $35-50(45)$ & $69-75(73)$ & $20-27(25)$ \\
\hline MG & $48-56(51)$ & $25-30(27)$ & $120-170(145)$ & $30-45(3)$ & $172-210(194)$ & $18-24(22)$ \\
\hline \multicolumn{7}{|l|}{ LG } \\
\hline Laminae $3-6$ & $15-18(17)$ & $15-20(18)$ & 0 & - & $65-85(75)$ & $10-20(18)$ \\
\hline Laminae $1-2$ & $19-23(21)$ & $15-20(18)$ & 0 & - & $60-75(62)$ & $10-25(20)$ \\
\hline S layer & $0-1(1)$ & $15-20(18)$ & $50-55(52)$ & $15-20(18)$ & $55-60(53)$ & $12-18(16)$ \\
\hline \multicolumn{7}{|l|}{ Basal ganglia } \\
\hline $\mathrm{CN}$ & $20-24(21)$ & $12-18(16)$ & $-a$ & $12-18(16)$ & $88-102(92)$ & $20-25(22)$ large \\
\hline $\mathrm{Pu}$ & $22-26(24)$ & $12-18(16)$ & $-a$ & $12-18(16)$ & $92-101(98)$ & $12-15(14)$ small \\
\hline Globus pallidus & $11-28(21)$ & $25-45(39)$ & 0 & - & $11-25(20)$ & $25-35(30)$ \\
\hline $\mathrm{SNc}$ & $0-3(1)$ & $25-35(30)$ & 0 & - & $38-45(40)$ & $22-30(28)$ \\
\hline $\mathrm{SNr}$ & $29-40(35)$ & $26-36(31)$ & 0 & - & $31-54(35)$ & $20-35(27)$ \\
\hline $\mathrm{Sb}$ & $0-4(3)$ & $6-12(10)$ & 0 & - & $36-51(39)$ & $16-25(20)$ \\
\hline \multicolumn{7}{|l|}{ Hypothalamus } \\
\hline DMH & $100-120(110)$ & $10-12$ & $80-92(85)$ & $10-12$ & $200-220(210)$ & $10-12(11)$ \\
\hline VMH & 0 & - & \multicolumn{2}{|c|}{ labeling too dense to count } & $390-403(400)$ & $10-12(11)$ \\
\hline MMN & 0 & - & \multicolumn{2}{|c|}{ labeling too dense to count } & $161-199(180)$ & $10-15(13)$ \\
\hline LMN & $28-32(30)$ & $20-22$ & 0 & & $102-121(115)$ & $15-18(17)$ \\
\hline
\end{tabular}

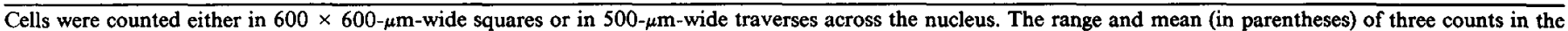
same animal are given. For abbreviations, see Appendix.

a Homogeneity of cell and neuropil labeling makes counting unsatisfactory (see Results).

habenulopeduncular tract, medial lemniscus, medial longitudinal bundle, or oculomotor nerve (Figs. 11-13).

\section{Basal ganglia and substantia nigra}

Many cell bodies are stained in the caudate nucleus, nucleus accumbens, and putamen, far more than those identified by labeling in the in situ hybridization preparations. Counts show up to 140 stained somata per $600-\mu \mathrm{m} \times 600-\mu \mathrm{m}$ field. These include a vast majority of small- to medium-sized cells measuring $10-15 \mu \mathrm{m}$ in diameter and a very small number of larger cells with long processes and somata measuring $18-25 \mu \mathrm{m}$ in diameter. The neuropil is moderately densely stained, less than 

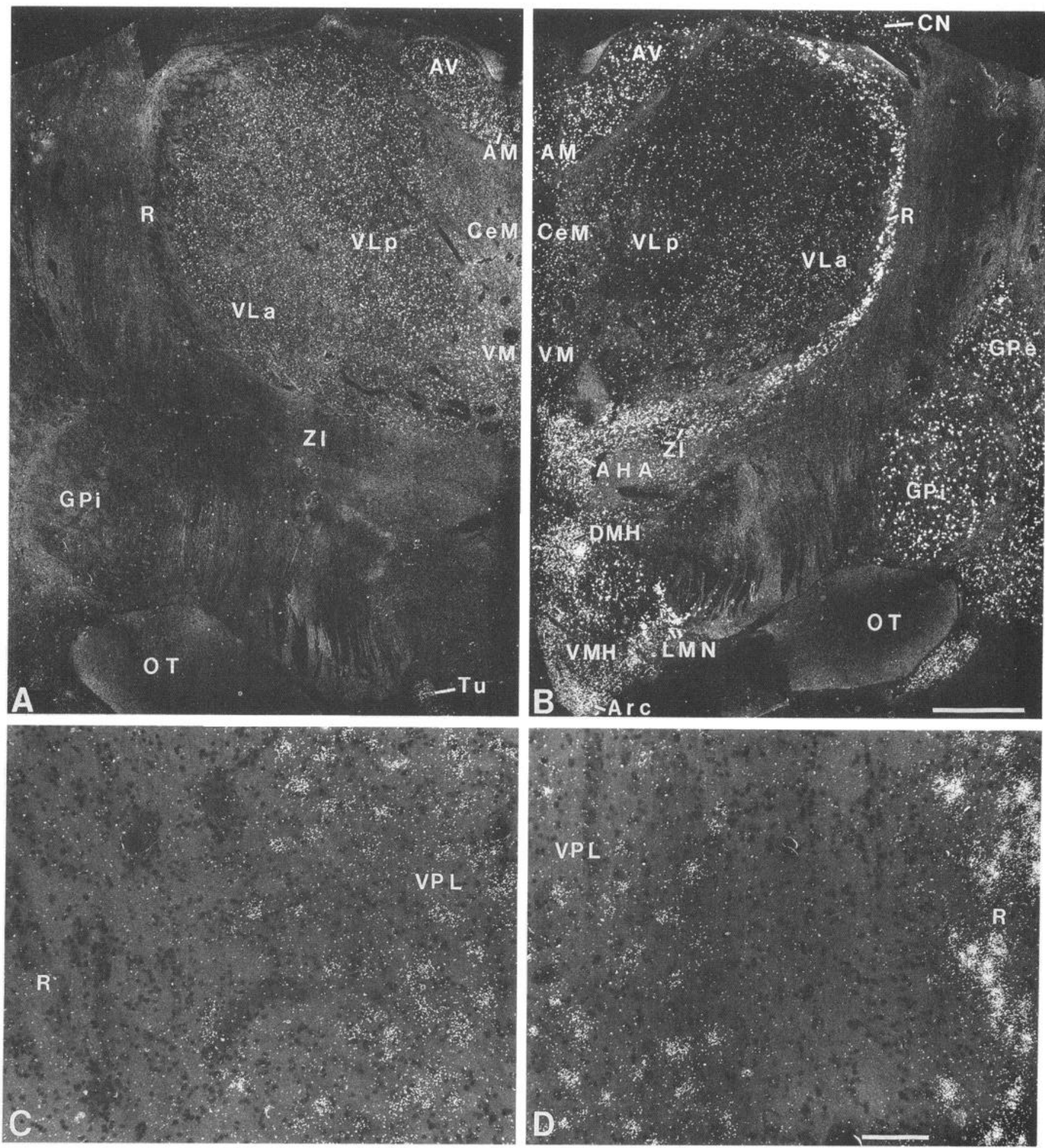

Figure 5. $A$ and $B$, CAM II kinase- $\alpha(A)$ and GAD $(B)$ probe hybridization in adjacent frontal sections through the anterior part of the thalamic ventral nuclear complex. Note lack of CAM II kinase- $\alpha$ gene expression in the ventral thalamus $(R, Z I)$, in the globus pallidus $(G P i)$, and in large parts of the hypothalamus. Scale bar, $2 \mathrm{~mm}$. $C$ and $D$, CAM II kinase- $\alpha(C)$ and GAD $(D)$ probe hybridization over adjacent parts of the reticular $(R)$ and ventral posterior lateral $(V P L)$ nuclei. Note lack of labeling of the reticular nucleus in $C$ and smaller labeled cells in $V P L$ in $D$. Scale bar, $50 \mu \mathrm{m}$. For other abbreviations, see Appendix.

the cerebral cortex but more than most of the thalamus, and there is a tendency for the stained cells to form large clumps, especially in the caudate nucleus (Fig. 12).

The claustrum contains many stained somata and a densely stained neuropil approaching in density the intense staining of the overlying cerebral cortex (Fig. 12).

The globus pallidus contains no immunoreactive cells, and though numerous, coarse immunoreactive fibers pass through 

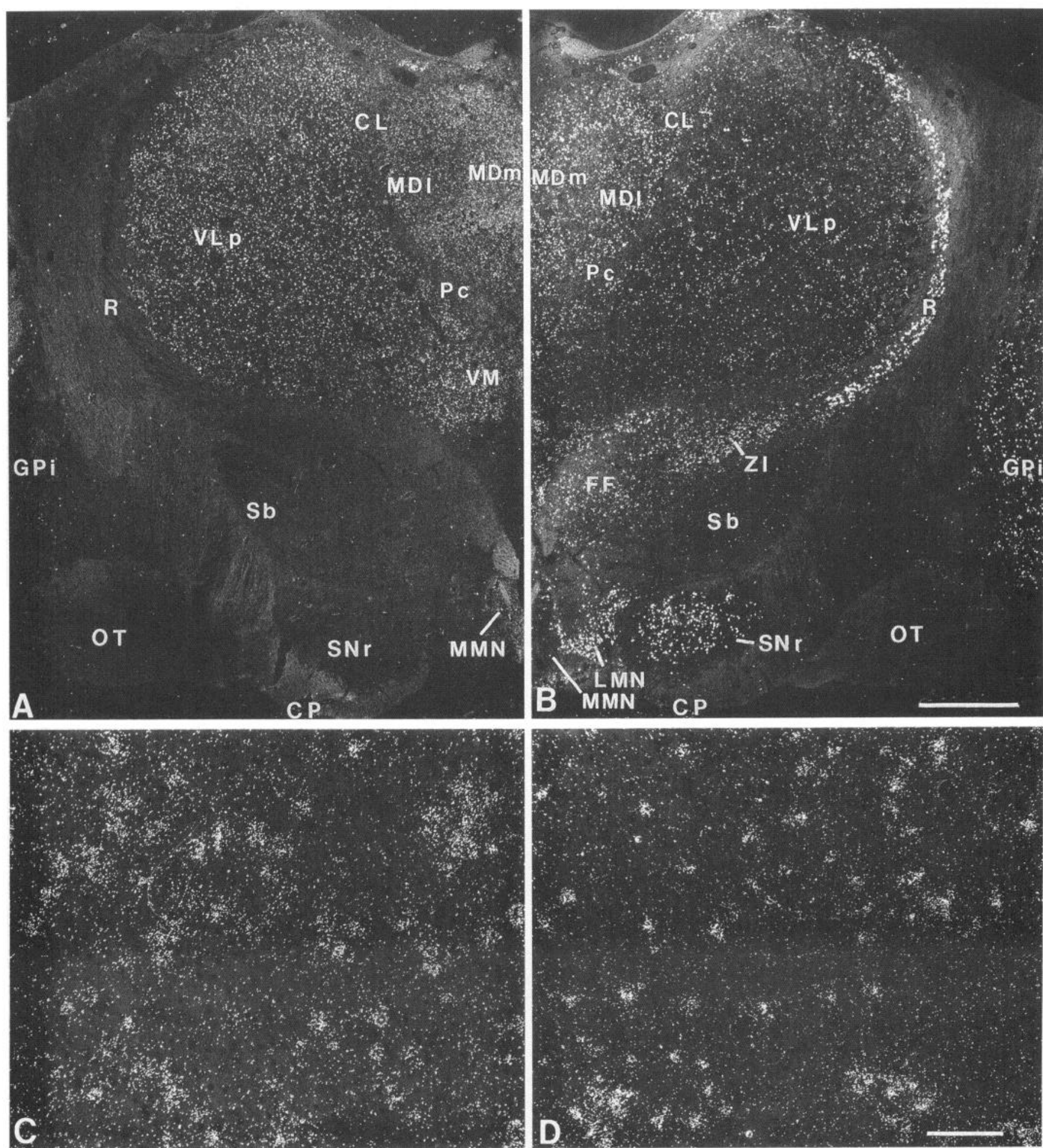

Figure 6. $A$ and $B$, CAM II kinase- $\alpha(A)$ and GAD $(B)$ probe hybridization in adjacent frontal sections approximately through the junction of anterior and middle thirds of the thalamus. Note differential hybridization patterns in the two divisions $(M D m, M D l)$ of the mediodorsal complex and in the mamillary nuclei $(L M N, M M N)$, lack of CAM II kinase- $\alpha$ probe hybridization in the subthalamic nucleus $(S b)$ and substantia nigra pars reticulata $(S N r)$, and paucity of GAD probe-hybridized cells in the subthalamic nucleus $(S b)$. Scale bar, $2 \mathrm{~mm}$. $C$ and $D$, CAM II kinase- $\alpha(C)$ and GAD $(D)$ probe hybridization in the medial, magnocellular division of the mediodorsal nucleus. Note differences in sizes of clusters of label putatively indicative of differences in sizes of labeled cells. Scale bar, $50 \mu \mathrm{m}$. For other abbreviations, see Appendix.

it (where they are cut in both cross and longitudinal section in the frontal sections of the brain) and accumulate around its periphery, its neuropil is singularly lacking in immunoreactivity (Fig. 12). Immunoreactive, terminal-like puncta are completely absent. The large cells of the basal nucleus of Meynert are strongly immunoreactive (Fig. 12). The neuropil of the substantia innominata is moderately densely stained.

The pars reticulata of the substantia nigra contains no im- 

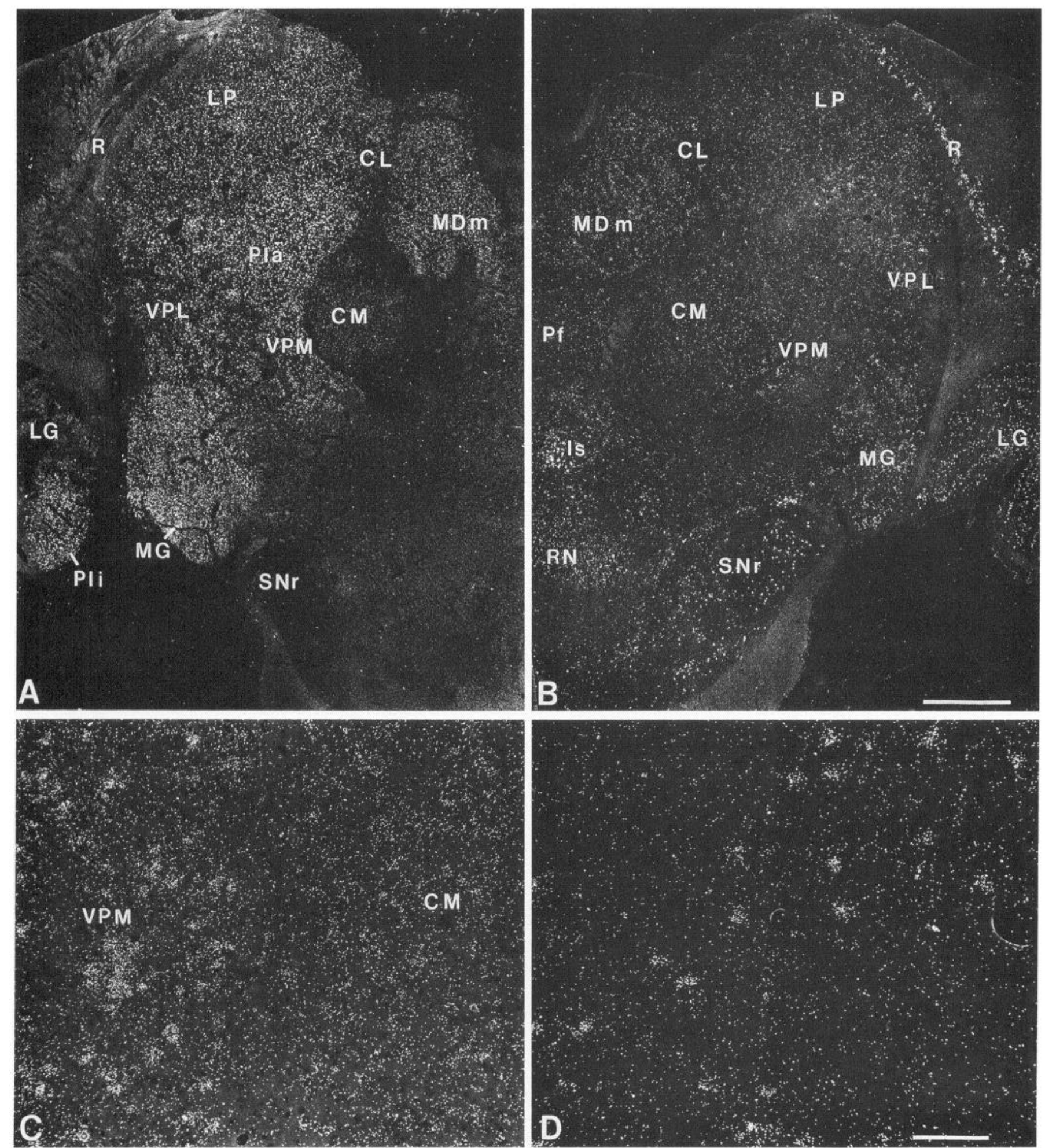

Figure 7. $A$ and $B$, CAM II kinase- $\alpha(A)$ and $\operatorname{GAD}(B)$ probe hybridization in adjacent frontal sections through the posterior third of the thalamus. In $A$, note lower density of CAM II kinase- $\alpha$ labeling in the nuclei of the intralaminar complex $(C L, C M)$ and weak or absent labeling of the midbrain. In $B$, note GAD labeling of the red nucleus $(R N)$ and interstitial nucleus of Cajal (Is). Scale bar, $2 \mathrm{~mm}$. $C$, Differential CAM II kinase$\alpha$ probe hybridization in the adjacent ventral posterior medial $(V P M)$ and centre médian $(C M)$ nuclei. $D$, GAD probe hybridization to small neurons of the centre médian nucleus. Scale bar, $50 \mu \mathrm{m}$. For other abbreviations, see Appendix.

munoreactive cell somata. Stained fibers of the striatonigral pathway that cross the cerebral peduncle can be seen entering it. It has a densely immunoreactive neuropil characterized by the presence of numerous punctate, immunoreactive structures resembling axon terminals (Fig. 13). The pars compacta proper of the substantia nigra contains no obvious immunoreactive cells, but its dorsal border is outlined by numerous stained, spindle-shaped cells that penetrate into it in small clumps. 

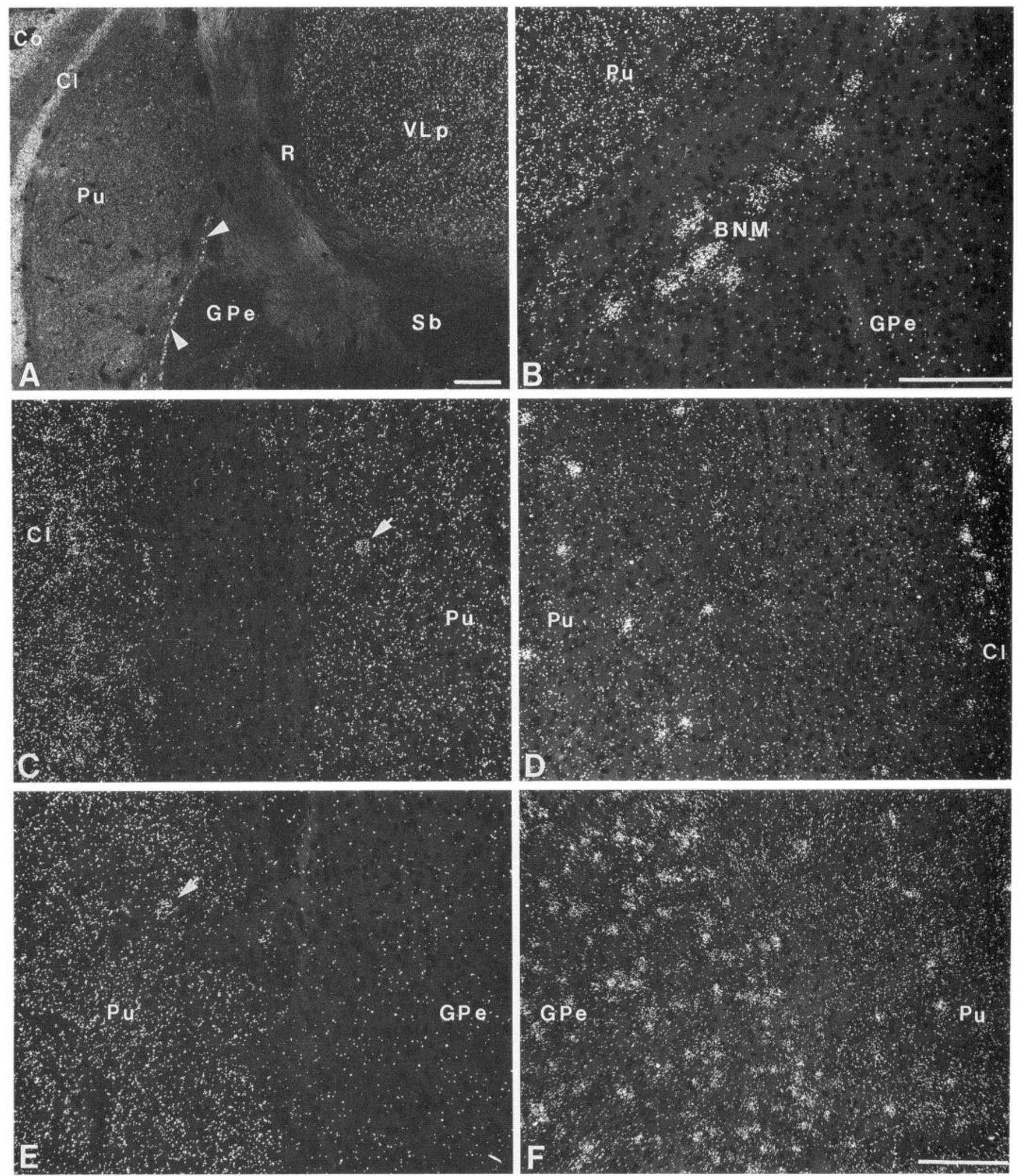

Figure 8. CAM II kinase- $\alpha(A-C, E)$ and $\operatorname{GAD}(D, F)$ probe hybridization in the basal ganglia. $A$ shows dense CAM II kinase- $\alpha$ labeling of the insular cortex $(\mathrm{Co})$, claustrum $(\mathrm{Cl})$, putamen $(\mathrm{Pu})$, and basal nucleus of Meynert (arrowheads), but lack of labeling of the subthalamic nucleus $(\mathrm{Sb})$ and external division of the globus pallidus $(G P e)$. $B$ shows the putamen, basal nucleus of Meynert, and globus pallidus at higher magnification from another section. $C$ and $D$ and $E$ and $F$ are paired sections through adjacent parts of the claustrum $(C l)$ and putamen $(P u)$ and of the putamen $(P u)$ and external division of the globus pallidus (GPe). CAM II kinase- $\alpha$ probe hybridization is dense and largely homogeneous in the putamen and claustrum $(C, E)$, with few grain clusters indicative of labeled cell somata (arrows) visible (cf. Fig. 1). GAD probe hybridization $(D, F)$ is more obviously cellular, and by contrast with $A$ and $E, F$ shows numerous labeled cells in the globus pallidus ( $G P e$ ). For other abbreviations, see Appendix. Scale bars: $A, 1 \mathrm{~mm} ; B$ and $C-F, 100 \mu \mathrm{m}$. 

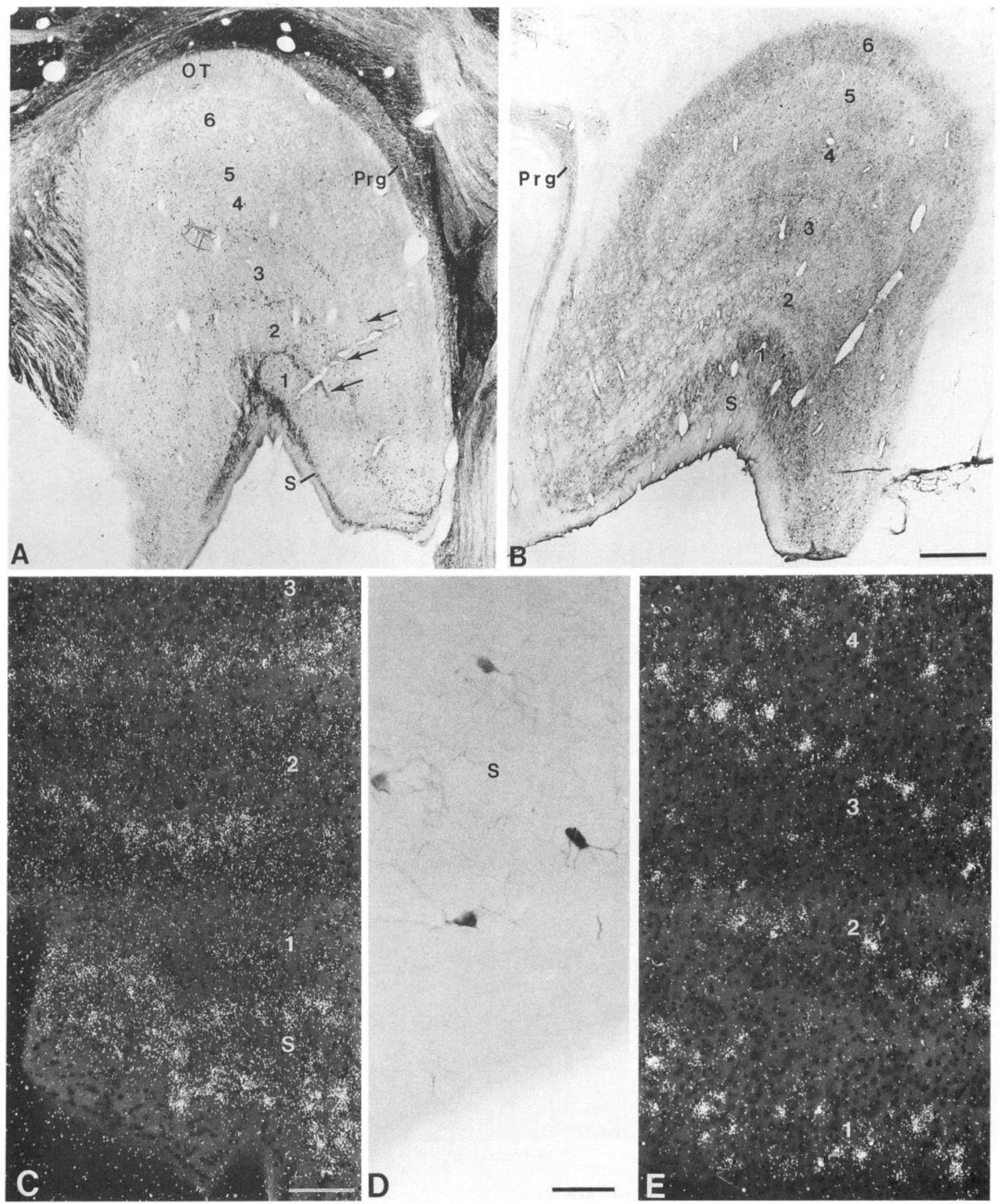

Figure 9. Frontal sections through the dorsal lateral geniculate (laminae $1-6$ ) and pregeniculate (Prg) nuclei stained immunocytochemically for CAM II kinase- $\alpha(A)$ or GABA $(B) . B$ is from material prepared for Hunt et al. (1991). In $A$, cell staining is confined to the $S$ layer and certain interlaminar (arrows) zones. In $B$, cells are stained in all layers. Scale bar, $500 \mu \mathrm{m}$. A higher magnification view of $S$ layer cells immunoreactive for CAM II kinase- $\alpha$ appears in $D$. Scale bar, $10 \mu \mathrm{m}$. $C$ and $E$, CAM II kinase- $\alpha$ probe hybridization in the $S$ layers and interlaminar zones $(C, 1-$ 3 ) and GAD probe hybridization in a proportion of the cells of principal laminae $1-4(E)$. Scale bar, $100 \mu \mathrm{m}$. 

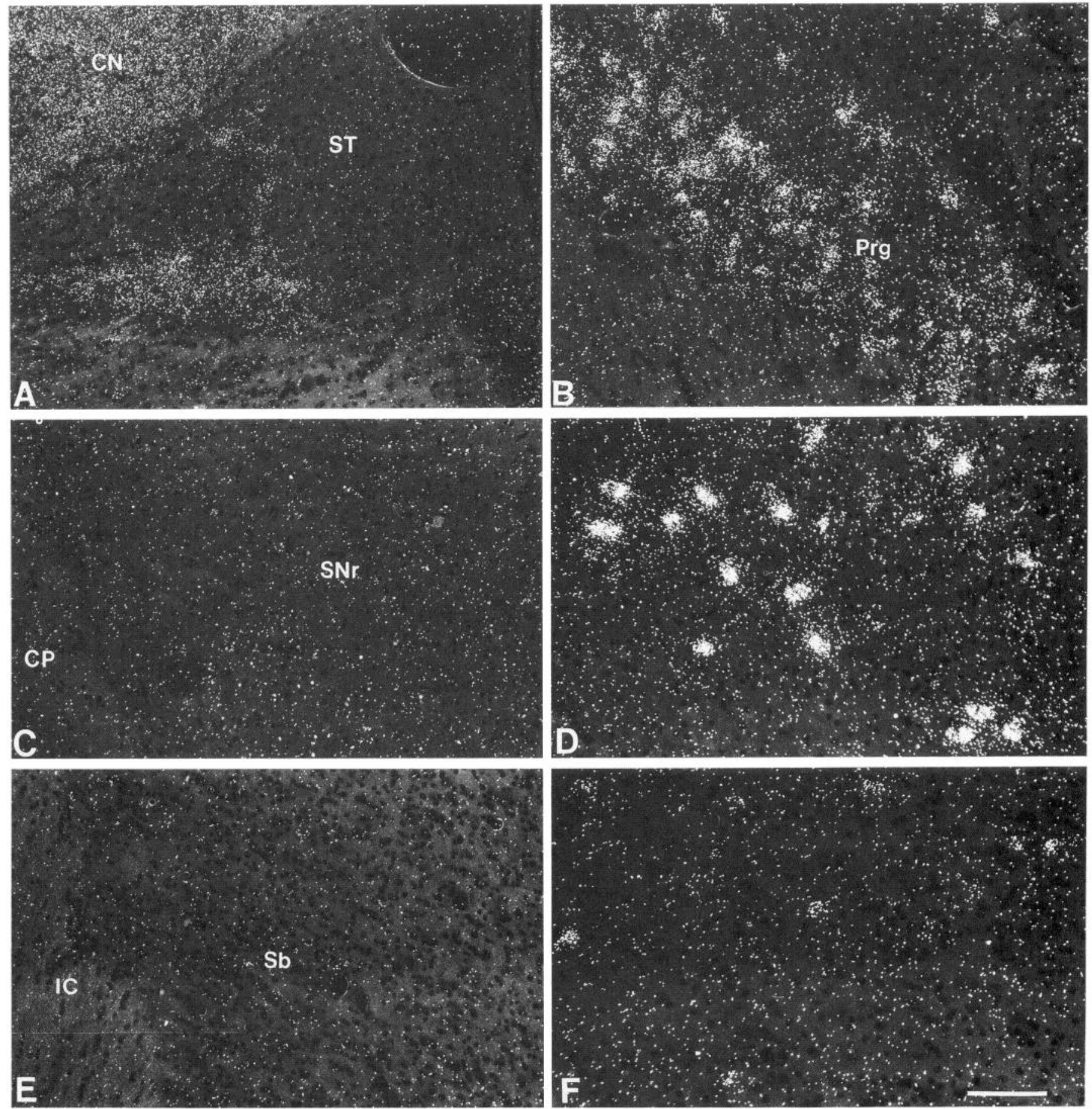

Figure 10. $A$ and $B$, CAM II kinase- $\alpha$ probe hybridization in the caudate nucleus $(C N)$ and bed nucleus of the stria terminalis $(S T ; A)$ and in the pregeniculate nucleus $(\operatorname{Prg}, B) . C$ and $D$ and $E$ and $F$ are paired sections through the substantia nigra pars reticulata $(S N r)$ and adjacent cerebral peduncle $(C P)$ and through the subthalamic nucleus $(S b)$ and adjacent internal capsule (IC). Note lack of CAM II kinase- $\alpha$-positive cells in the pars reticulata $(C)$ and subthalamic nucleus $(E)$ and heavy labeling for GAD mRNA in the pars reticulata $(D)$ but weak labeling for GAD mRNA in a few cells of the subthalamic nucleus $(F)$. Scale bar, $100 \mu \mathrm{m}$ for $A-F$.

\section{Thalamus}

In the ventral thalamus, the reticular nucleus contains no cell or neuropil staining (Fig. 11). The zona incerta is similar except for a few stained cells found in its ventralmost aspect. The pregeniculate nucleus contains numerous stained fibers and small, stained cell somata.
In the epithalamus, there is no immunoreactive staining of the paraventricular or habenular nuclei.

In the dorsal thalamus, all nuclei showing in situ hybridization of the CAM II kinase- $\alpha$ riboprobe show immunoreactive cells in approximately the same proportions. In most nuclei, neuropil staining is weaker than in the striatum or substantia nigra pars reticulata. The thalamic nuclei showing densest neuropil stain- 

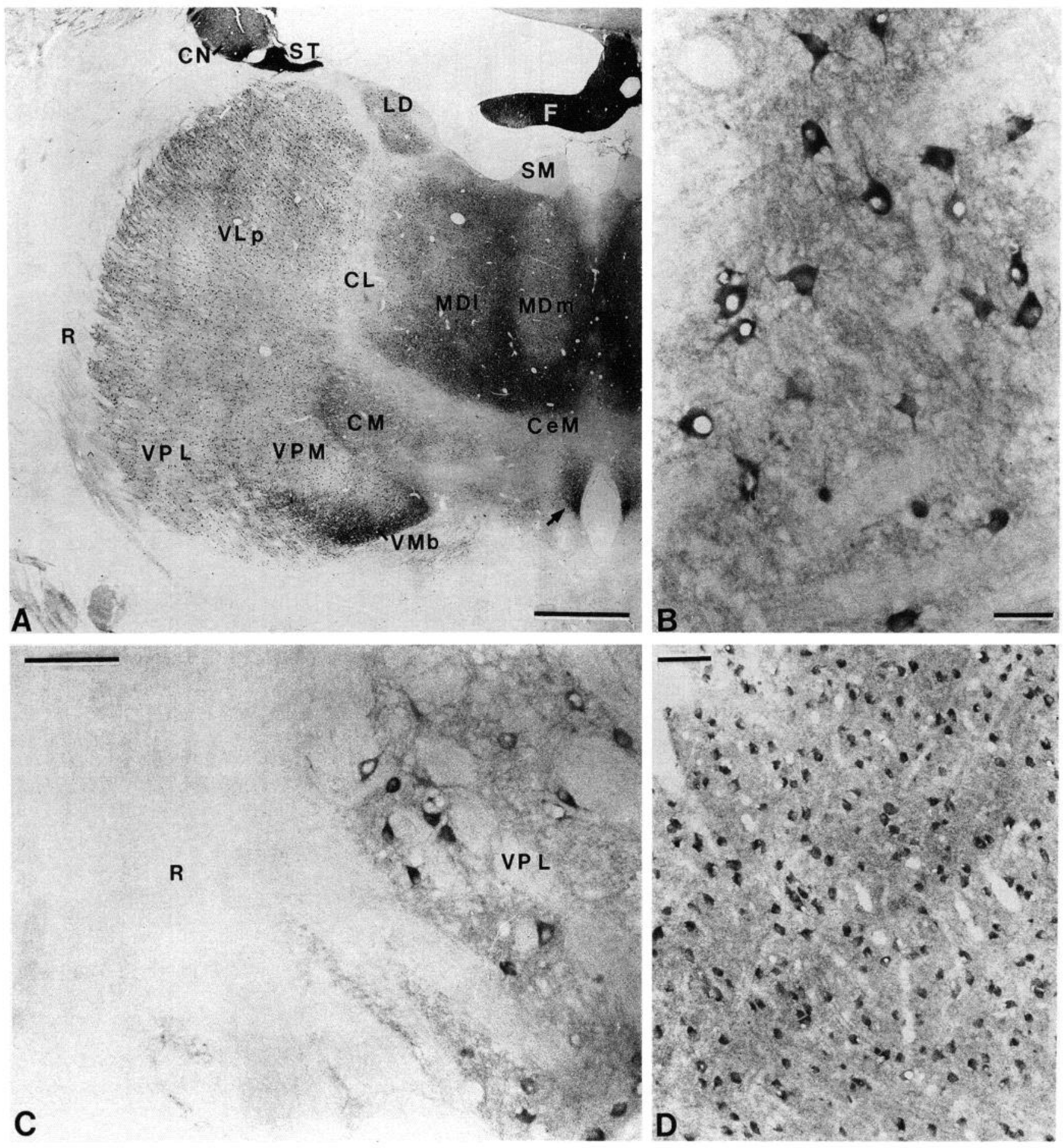

Figure 11. A, Frontal section through the middle of the thalamus, stained immunocytochemically for CAM II kinase- $\alpha$. Note lack of staining of reticular nucleus cells $(R)$, differential staining of the two divisions of the mediodorsal nucleus $(M D l, M D m)$, lower intensity of staining of the intralaminar nuclei $(C L, C M, C e M)$, and staining of stria terminalis $(S T)$ and fornix $(F)$ but not of stria medullaris $(S M)$. The arrow indicates immunoreactivity in the region of transition from diencephalon to periaqueductal gray matter. Scale bar, $2 \mathrm{~mm}$. $B$, Large CAM II kinase- $\alpha-$ immunoreactive cells in the ventral lateral posterior nucleus of the thalamus. Scale bar, $50 \mu \mathrm{m}$. $C$, CAM II kinase- $\alpha$-immunoreactive cells and neuropil in the ventral posterior lateral $(V P L)$ thalamic nucleus and lack of cellular immunoreactivity in the reticular nucleus $(R)$. Scale bar, 100 $\mu \mathrm{m}$. $D$, CAM II kinase- $\alpha$-immunoreactive cells in the lateral pulvinar nucleus. Scale bar, $100 \mu \mathrm{m}$. For other abbreviations, see Appendix.

ing are the lateral division of the mediodorsal, the basal ventral medial, and the lateral dorsal nuclei (Fig. 11). Those of the remainder of the ventral nuclear complex and those of the medial geniculate complex show moderate to dense staining. Nuclei showing the weakest staining are the anterodorsal and the in- tralaminar nuclei, including the centre médian and parafascicular. Neuropil staining in these nuclei is virtually absent, and immunoreactive staining of cell somata is so weak that they can only be identified under the high power of the microscope. Their numbers, however, are relatively high in the intralaminar nuclei 

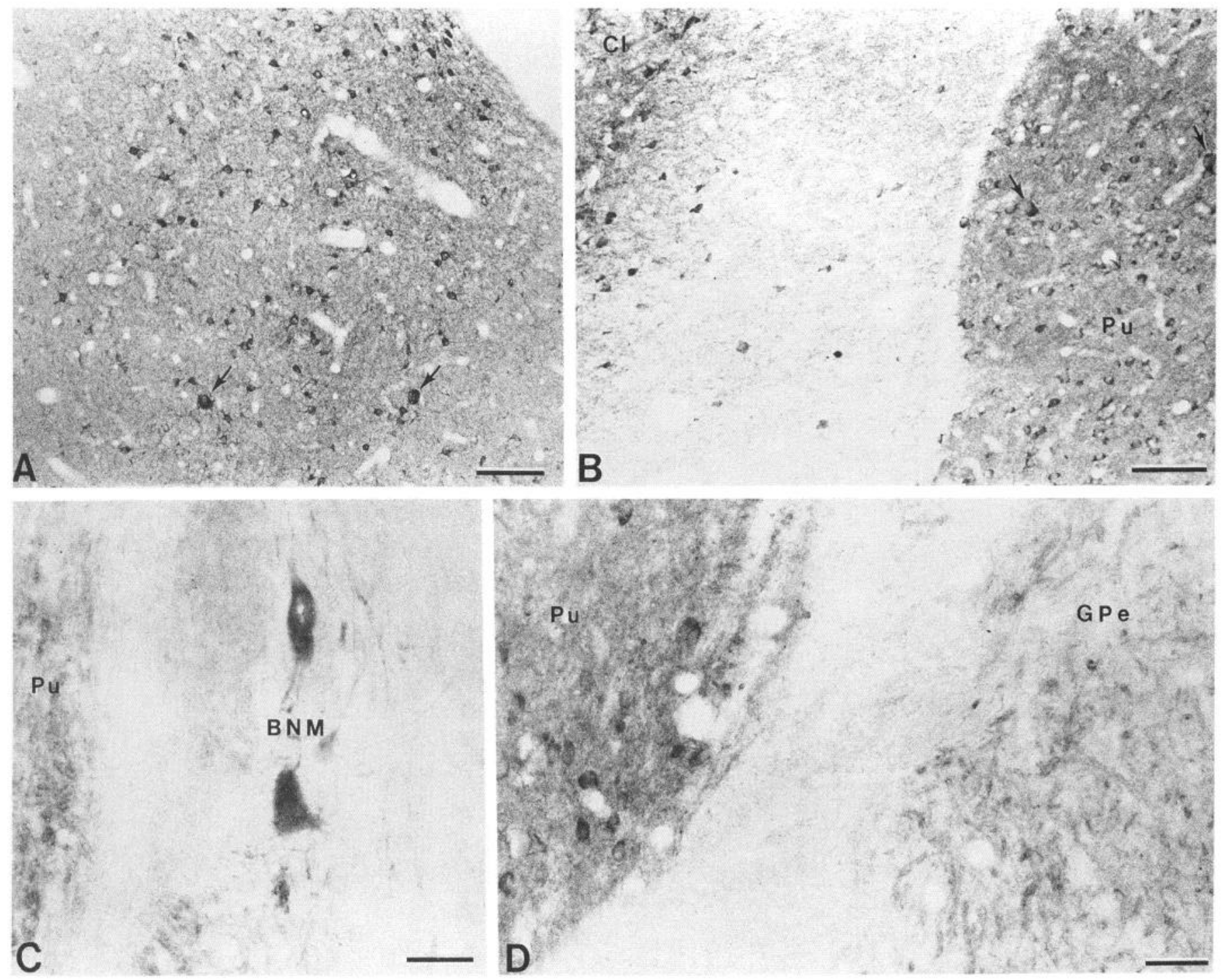

Figure 12. A, CAM II kinase- $\alpha$-immunoreactive cells and neuropil concentrated in a large island in the caudate nucleus. Arrows indicate two larger stained cells. Scale bar, $100 \mu \mathrm{m} . B$, CAM II kinase- $\alpha$-immunoreactive staining of the claustrum $(C l)$ and putamen $(P u)$. Arrows indicate two large stained cells. Scale bar, $100 \mu \mathrm{m}$. $C$, CAM II kinase- $\alpha$ immunoreactivity in large cells of the basal nucleus of Meynert (BNM) and in the adjacent putamen $(P u)$. Scale bar, $25 \mu \mathrm{m}$. $D$, CAM II kinase- $\alpha$ immunoreactivity in cells and neuropil of the putamen $(P u)$ but apparently in fibers only in the external division of the globus pallidus $(G P e)$. See Figure $13 A$. Scale bar, $50 \mu \mathrm{m}$.

but low in the anterodorsal nucleus. The limitans-suprageniculate, posterior, and magnocellular medial geniculate nuclei are very similar in appearance to the intralaminar nuclei. The medial division of the mediodorsal nucleus shows large, intensely stained cells but only weak neuropil staining (Fig. 11), contrasting with the dense neuropil staining of the lateral division, and with the relative densities of label seen in the in situ hybridization pattern (Figs. 2, 6). The dorsal lateral geniculate nucleus shows staining of cells confined to the $\mathrm{S}$ layers and interlaminar zones (Fig. 9).

\section{Hypothalamus}

The densest immunoreactive staining of the neuropil and greatest number of immunoreactive cells are found in the ventral medial, medial mamillary, and tuberal nuclei (Fig. 13), following closely the in situ hybridization pattern (Figs. 2-5). Other hypothalamic nuclei and areas show weak neuropil staining and scattered, but usually well-stained somata. The lateral mamillary nucleus contains a densely stained neuropil but few or no stained somata.

\section{Midbrain}

The substantia nigra has been described above. The central gray matter and peripeduncular nucleus show moderate neuropil staining and a moderate concentration of immunoreactive cells. Scattered, well-stained cells in a weakly immunoreactive neuropil are found throughout the pretectal nuclei and in the interpeduncular nuclei. There is no staining of the red nucleus or oculomotor nucleus. These patterns, again, follow the in situ hybridization pattern (Fig. 2).

\section{Discussion}

The principal findings of this study are the complementarity in the distribution of cells showing gene expression for CAM II 

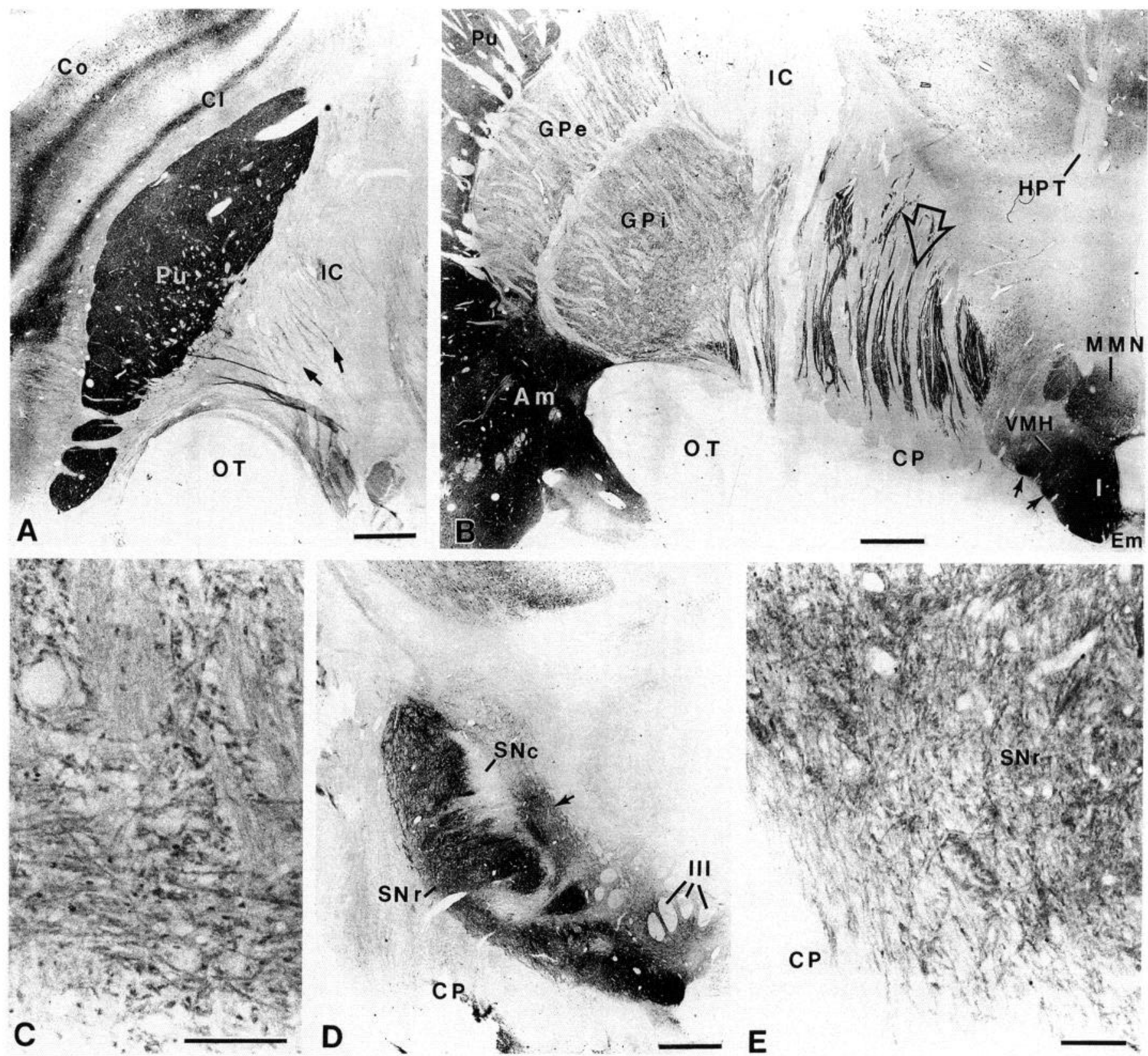

Figure 13. A, Dense CAM II kinase- $\alpha$ immunoreactivity in the insular cortex $(\mathrm{Co})$, claustrum $(\mathrm{Cl})$, and putamen $(\mathrm{Pu})$ and immunoreactivity in fibers (arrows) from the putamen that traverse the internal capsule $(I C)$. Scale bar, $1 \mathrm{~mm} . B$, CAM II kinase- $\alpha$-immunoreactive, putative striatonigral fibers (arrow) traversing the cerebral peduncle $(C P)$. Note staining of fibers of passage in globus pallidus $(G P e$, $G P i)$, lack of fiber staining in the habenulopeduncular tract $(H P T)$, and dense immunoreactivity in the mamillary $(M M N)$, ventral medial $(V M H)$, infundibular $(I)$, and tuberal (arrows) nuclei of the hypothalamus. Scale bar, $1 \mathrm{~mm}$. $C$, Fibers immunoreactive for CAM II kinase- $\alpha$ cut in both longitudinal and cross section in the internal segment of the globus pallidus. Scale bar, $50 \mu \mathrm{m}$. $D$ and $E$, Dense CAM II kinase- $\alpha$ immunoreactivity in fibers and neuropil of the substantia nigra pars reticulata $(S N r)$. Pars compacta $(S N c)$ is not stained, except for region (arrow) intruding on its dorsomedial border. Fascicles of oculomotor nerve $(I I I)$ are similarly unstained. For other abbreviations, see Appendix. Scale bars: $D, 1 \mathrm{~mm} ; E, 25 \mu \mathrm{m}$.

kinase- $\alpha$ or GAD, and the presence of large amounts of CAM II kinase- $\alpha$ mRNA in the neuropil in most regions in which CAM II kinase- $\alpha$-positive cells are found. The results suggest that CAM II kinase- $\alpha$, though a ubiquitous forebrain protein, is not uniformly distributed and, instead, appears to be associated with non-GABAergic cells and with certain anatomical pathways. These observations and interpretations each raise several points for discussion.
The differential distribution of GAD- and CAM II kinase- $\alpha-$ expressing cells is particularly evident in nuclei such as the globus pallidus (both segments), basal nucleus of Meynert, reticular nucleus of the thalamus, laminae of the dorsal lateral geniculate nucleus, substantia nigra pars reticulata, ventral medial hypothalamic nucleus, and medial mamillary nucleus, in all of which cells exhibit discernible levels of mRNA for one protein but not for the other. Even in the numerous nuclei in 
which cell populations show hybridization of both GAD and CAM II kinase- $\alpha$ riboprobes, in many of them the evidence of the cell counts and differences in the inferred sizes of labeled cells strongly suggest that GAD-expressing and CAM II kinase$\alpha$-expressing cells form two separate populations. This interpretation should be qualified to the extent that each population could conceivably express such low levels of the other mRNA that it would be undetectable by the methods used.

\section{Thalamus}

Nuclei of the dorsal thalamus contain two fundamental cell populations: relay or projection neurons and GABAergic interneurons (Hendrickson et al., 1983; Penny et al., 1983; Spreafico et al., 1983; Fitzpatrick et al., 1984; Montero and Singer, 1985; Montero, 1986; Jones and Hendry, 1989). There is reason to believe that in the dorsal thalamus, the CAM II kinase- $\alpha-\mathrm{ex}$ pressing population of cells represents the thalamocortical and thalamostriatal projection neurons and that the GAD-expressing population represents the local circuit neurons: GABA-immunoreactive neurons in monkey dorsal thalamic nuclei account for approximately $25-35 \%$ of the total neuronal population and are consistently smaller than the relay neurons (Montero and Zempel, 1986; Hunt et al., 1991). In the present study, the larger sizc of the CAM II kinasc- $\alpha$-positive cells, their relative proportions, and the absence of coexpression of GAD and CAM II kinase in pure populations of GABA neurons in the reticular nucleus (Houser et al., 1980; Oertel et al., 1983; Yen et al., 1985), globus pallidus (Smith et al., 1987a), and pars reticulata of the substantia nigra (Smith et al., 1987a) make it likely that the CAM II kinase- $\alpha$-positive cells of the dorsal thalamus are the relay neurons.

CAM II kinase- $\alpha$ cannot, however, be regarded as a generic marker for thalamic relay cells. In the dorsal lateral geniculate nucleus, CAM II kinase- $\alpha$ is clearly expressed by only one small population of relay neurons, namely, those of the $S$ layers and interlaminar zones. The cells in these parts of the nucleus project to superficial layers (I-III) of the visual cortex (Fitzpatrick et al., 1983; Livingstone and Hubel, 1983). The principal layers project primarily to layers IV and VI (Hubel and Wiesel, 1977). GAD-cxpressing cells in the principal layers of the nucleus account for approximately $25-30 \%$ of the total cell population (Montero and Zempel, 1986; Hendry, 1991), and the present findings are in the same range. Therefore, the remaining cells, which do not express CAM II kinase- $\alpha$, are clearly relay cells.

\section{Striatum}

In the striatum, though GAD-expressing cells are readily identifiable, the overall density of labeling and the lack of resolution between labeled cells and neuropil in CAM II kinase- $\alpha$ in situ hybridization preparations preclude reliable identification of the total cell population expressing CAM II kinase- $\alpha$. Therefore, it could not be determined whether the two mRNAs occupy separate or overlapping cell populations. Cell counts revealed that approximately $23 \%$ of the striatal cells contain GAD mRNA, which approaches the percentage of GABA-immunoreactive cells reported in the squirrel monkey striatum by Smith et al. (1987b). Approximately $75 \%$ of the striatal neurons are immunoreactive for CAM II kinase- $\alpha$. Given the evidence for a lack of colocalization elsewhere in the forebrain, these percentages could indicate that GAD- and CAM II kinase- $\alpha$-expressing neurons form complementary populations in the striatum, as well.
The striatal cell population, as described in nonprimates, is a mixed one, with six or more types being identified by various authors. The same basic cell types are present in primates (Cajal, 1900; Fox et al., 1971). A medium-sized, dendritic-spine-bearing cell type has been estimated to comprise more than $90 \%$ of the total cell population (Kemp and Powell, 1971a; DiFiglia et al., 1976; Chang et al., 1982). This neuronal type is thought to include both projection neurons and GABAergic neurons (Grofová, 1975; Ribak et al., 1979; Somogyi and Smith, 1979; Preston et al., 1980; Wilson and Groves, 1981; Oertel and Mugnaini, 1984; Bolam et al., 1985; Gerfen, 1985, 1988; Somogyi et al., 1985; Penny et al., 1986; Chesselet et al., 1987; Chesselet and Robbins, 1989). Whether all spiny neurons contain GABA and whether all projecting neurons are GABAergic have not been determined (for a review, see Graybiel and Ragsdale, 1983).

The remaining aspiny neurons are thought to be mainly interneurons and include a medium-sized type that is GABA immunoreactive (Bolam et al., 1984), a large type that is ChAT immunoreactive (Bolam et al., 1984; Phelps et al., 1985), and other medium-sized types that are immunoreactive for various neuropeptides, including somatostatin, neuropeptide $Y$, enkephalin, dynorphin, and tachykinins (Elde et al., 1976; Brownstein et al., 1977; Hökfelt et al., 1977; Hong et al., 1977; Kanagawa et al., 1977; Jessell et al., 1978; Ljungdahl et al., 1978; Sar et al., 1978; Pickel et al., 1980; Finlay et al., 1981; Del Fiacco et al., 1982; DiFiglia et al., 1982; Graybiel et al., 1982; Vincent et al., 1982a,c, 1983; Bolam et al., 1983; Haber and Nauta, 1983; Takagi et al., 1983; Vincent and Johansson, 1983; Aronin et al., 1984; Beckstead and Kersey, 1985; Beal et al., 1986; Chesselet and Graybiel, 1986; Penny et al., 1986; Smith and Parent, 1986b; Aoki and Pickel, 1989). In a number of instances, the presence of mRNAs for the precursors of these peptides has been demonstrated by in situ hybridization histochemistry (Young et al., 1986; Chesselet et al., 1987; Gerfen and Young, 1988; Chesselet and Robbins, 1989; Weiss and Chesselet, 1989). Some cells show colocalization of GABA and peptide immunoreactivity (Aronin et al., 1984; Penny et al., 1986), but the incidence of this has also been reported to be slight (Aoki and Pickel, 1989; Chesselet and Robbins, 1989).

Two studies of the rat striatum have indicated the existence of two classes of GAD-immunoreactive neurons on the basis of differential staining intensity (Oertel and Mugnaini, 1984; Bolam et al., 1985). Certain of the cells show very intense immunoreactive staining, while others stain more weakly. In a recent study, Chesselet et al. (1987) also showed two types of GAD cells by in situ hybridization histochemistry in the rat and mouse striatum. One of these, thought to be equivalent to the densely GAD-immunoreactive cells, showed heavy mRNA labeling, and a second, thought to be equivalent to the weakly immunoreactive cells, showed light labeling. The cRNA probe used was derived from a cat GAD cDNA (Kobayashi et al., 1987) that would recognize the same transcript as the monkey GAD riboprobe used in the present study (Benson et al., 1991a). However, no clear indications of two populations of GAD cells were seen in the present study.

The GAD-expressing population demonstrated by in situ hybridization (23\%) is too small to account for all the medium spiny cells of the striatum. Therefore, CAM II kinase- $\alpha-e x-$ pressing cells, which account for $75 \%$ of the population, potentially will include non-GABAergic, medium spiny, and large aspiny cholinergic neurons, and medium aspiny peptidergic neurons. The large cells shown to be immunoreactive for CAM II 
kinase- $\alpha$ are similar to the large cholinergic cells described by others. It is possible that these are the cells whose somata are most obvious in the in situ hybridization preparations. In being larger, they may contain higher mRNA levels.

\section{Substantia nigra and subthalamic nucleus}

Although complementarity and a bimodal distribution of CAM II kinase- $\alpha$ - and GAD-expressing cells are features of many nuclei in the basal ganglia, diencephalon, and midbrain, cells of certain nuclei express neither. The most overt example of this is in the paraventricular nuclei of the epithalamus. The pars compacta of the substantia nigra is another, and to a considerable degree, the subthalamic nucleus is a third. In the pars compacta, CAM II kinase- $\alpha$ mRNA-positive cells only intrude on it from its borders, in the subthalamic nucleus no CAM II kinase- $\alpha$-positive cells are found, and in both the pars compacta and subthalamic nucleus, GAD mRNA-positive cells are extremely rare.

Immunocytochemical studies in the rat and monkey and in situ hybridization studies in the rat have consistently reported a lack of GAD- or GABA-immunoreactive cells in the subthalamic nucleus (Mugnaini and Oertel, 1985; Chesselet et al., 1987; Smith et al., 1987a; Smith and Parent, 1988; Benson et al., $1991 \mathrm{~b}$ ), though subthalamic cells in the cat accumulate, by retrograde axoplasmic transport, ${ }^{3} \mathrm{H}-\mathrm{GABA}$ injected into the globus pallidus (Nauta and Cuénod, 1982). The present results show the presence of a small number of lightly labeled GADexpressing cells in the nucleus of the monkey, but these may be so few and/or contain too little GAD protein or GABA to be detectable by immunocytochemistry.

\section{Hypothalamus}

Previous studies of GABA or GAD immunoreactivity in the hypothalamus have, to the best of our knowledge, been conducted on nonprimates, particularly rodents. All have remarked on the very high density of immunoreactive fiber and neuropil staining and the difficulty of identifying immunoreactive cell somata without colchicine treatment (e.g., Perez de la Mora et al., 1981; Vincent et al., 1982b; Tappaz et al., 1983; Mugnaini and Oertel, 1985; Van den Pol, 1986). Hypothalamic nuclei reported to contain the highest densities of GAD-immunoreactive fibers and neuropil include the following: arcuate nucleus, dorsomedial nucleus, ventral medial nucleus, perifornical region, medial and lateral parts of the mamillary body, median eminence, suprachiasmatic nucleus, and preoptic area; other related nuclei containing high densities include the fields of Forel and bed nucleus of the stria terminalis. After colchicine injcctions, GAD-immunoreactive cells became visible in the arcuate nucleus, perifornical region, and regions lateral and posterior to the medial mamillary nucleus (Vincent et al., 1982b).

Many of the nuclei and areas of the hypothalamus that were reported to contain high densities of GAD-immunoreactive fiber plexuses also show concentrations of GAD mRNA-expressing cells in the present study. Others, such as the medial mamillary and ventral medial nuclei, clearly do not, and it is likely that the presence of immunoreactivity in them reflects the presence of a GABAergic projection.

The connections of the hypothalamus are many and diverse (Swanson, 1987), and it would be inappropriate to review them in this paper. The two nuclear complexes that show the most obvious complementarity of GAD- and CAM II kinase- $\alpha$-expressing cells, the ventral medial and medial mamillary, have different patterns of input-output connections. It is possible that CAM II kinase- $\alpha$-expressing cells represent cells with longerprojecting axons, for example, from the ventral medial nucleus to the septum and amygdala and from the medial mamillary nucleus to the thalamus and brainstem tegmental nuclei, while GAD-expressing cells may form the basis of many shorter connections in the hypothalamus.

\section{Afferent pathways}

Immunoreactivity for CAM II kinase- $\alpha$ appears in certain fiber pathways and their terminations but not in others. This also argues for selectivity of CAM II kinase- $\alpha$ gene expression in the parent cells. Fibers of the striatonigral projection, those of the stria terminalis and the fornix, and significant numbers in the internal capsule and cerebral peduncle are CAM II kinase- $\alpha$ immunoreactive. Fibers in several other fiber tracts, notably the mamillothalamic tract, the stria medullaris, and habenulopeduncular tract, clearly are not. The latter two contain complements of GABAergic fibers (Gottesfeld et al., 1977, 1981; Nagy et al., 1978a). The pallido-subthalamic nucleus pathway is also reportedly GABAergic (Fonnum et al., 1978; Kita et al., 1983; Smith et al., 1990), and its nuclei of origin and termination are also not associated with the presence of CAM II kinase- $\alpha$ protein.

Fibers in the positive immunoreactive fiber tracts mentioned above arise from regions in which the parent cells show gene expression for CAM II kinase- $\alpha$, namely, the striatum, bed nucleus of the stria terminalis, amygdala, hippocampus, cerebral cortex, and thalamus (present results; D. L. Benson, P. J. Isackson, S. H. C. Hendry, and E. G. Jones, unpublished observations). The enzyme is therefore apparently transported along the axons of these cells, presumably for use at the axon terminals. At the terminalis, evidence from the squid giant synapse suggests that CAM II kinase, by phosphorylation of synapsin $I$, is involved in regulating synaptic vesicle movement (McGuinness et al., 1989) and promotes transmitter release (Llinás et al., 1985).

The pars reticulata of the substantia nigra and the lateral mamillary nucleus show heavy immunoreactivity for CAM II kinase- $\alpha$ in the neuropil, including in structures resembling terminal boutons. This argues for a CAM II kinase- $\alpha$-positive projection. However, the nuclei receiving the projection lack CAM II kinase- $\alpha$-expressing cells. Other afferent projections lack CAM II kinase- $\alpha$ but end in nuclei containing CAM II kinase- $\alpha$-expressing cells. For example, GABA neurons in the globus pallidus, substantia nigra pars reticulata, and thalamic reticular nucleus project to the dorsal thalamus, in which relay cells are CAM II kinase- $\alpha$ positive (Carpenter and Peter, 1972; Carpenter et al., 1975; Kim et al., 1976; Faull and Mehler, 1978; Kultas-Ilinsky et al., 1978, 1983; DiChiara et al., 1979; Herkenham, 1979; McLeod et al., 1980; Ohara et al., 1980; Montero and Scott, 1981; Starr and Kilpatrick, 1981; Penney and Young, 1981; DeVito and Anderson, 1982; Ueki, 1983; Francois et al., 1984; Ilinsky and Kultas-Ilinsky, 1984; Ilinsky et al., 1985; Yen et al., 1985). At certain synapses, therefore, there appears to be a dissociation of pre- and postsynaptic CAM II kinase- $\alpha$-linked mechanisms. Finally, the absence of CAM II kinase-immunoreactivity from the neuropil of the globus pallidus and subthalamic nucleus and the absence of CAM II kinase- $\alpha$ gene expression in pallidal and subthalamic cells suggest that at some synapses CAM II kinase- $\alpha$ may be absent from both the preand the postsynaptic sides. 


\section{Presynaptic distribution}

The absence of gene expression for CAM II kinase- $\alpha$ in many known populations of GABAergic neurons, as demonstrated in the present study, suggests that the enzyme may be absent from GABA-releasing terminals in many regions, including the pallidothalamic and nigrothalamic projections, the synapses made by axons of reticular nucleus cells and by axons and dendrites of thalamic interneurons on other thalamic cells, and the striatopallidal and pallidosubthalamic projections, all of which are reported to be GABAergic (Fonnum et al., 1978; Nagy et al., 1978b; Uno et al., 1978; DiChiara et al., 1979; Kilpatrick et al., 1980; McLeod et al., 1980; Starr and Kilpatrick, 1981; Penney and Young, 1983; Araki et al., 1985). The situation is less clear for the striatonigral projection (Francois et al., 1984; Smith and Parent, 1986a; Desbau et al., 1989; Jimenez-Castellanos and Graybiel, 1989), which indirect evidence suggests is GABAergic (Fonnum et al., 1974; Ribak et al., 1980, 1981; Walaas and Fonnum, 1980; Oertel et al., 1981; Oertel and Mugnaini, 1984; Penny et al., 1986). The present results indicate that striatonigral fibers and the neuropil of the pars reticulata of the substantia nigra in which they end are strongly immunoreactive for CAM II kinase- $\alpha$. If these fibers and putative terminals represent the GABAergic striatonigral projection, then they are clearly an exception to the other sites studied in which CAM II kinase- $\alpha$ is not expressed in GABA cells and does not appear in GABAergic pathways. We must conclude, therefore, either (1) that CAM II kinase- $\alpha$ and GAD are, unusually, coexpressed by the parent cells of the striatonigral projection; or (2) that separate CAM II kinase- $\alpha$ - and GAD-containing fibers exist in the projection. The overwhelming majority of CAM II kinase- $\alpha$-immunoreactive cells in the striatum would tend to favor the existence of a population of fibers in the striatonigral pathway that contains CAM II kinase- $\alpha$ only. The recently described pallidosubstantia nigra projection (Smith and Bolam, 1989), which is presumably GABAergic, cannot be the source of the CAM II kinase- $\alpha$ immunoreactivity in the pars reticulata, because no pallidal cells show the presence of CAM II kinase- $\alpha$ mRNA. Although the presence of a striatal cell population that coexpresses genes for CAM II kinase- $\alpha$ and for GAD mRNA could account for the discrepancy, this would be unexpected in view of the results in other regions. Therefore, until further work is carried out, we would favor the possibility that separate GABA and CAM II kinase- $\alpha$ striatonigral paths exist.

The globus pallidus, unlike the substantia nigra pars reticulata, does not show neuropil immunoreactivity for CAM II kinase- $\alpha$. This would tend to support the view that the striatopallidal pathway, also thought to be GABAergic, arises from a population of striatal GABA cells that do not express CAM II kinase- $\alpha$.

The expression of CAM II kinase- $\alpha$ in the large cells of the basal nucleus of Meynert suggests an association with cholinergic cells that may be reflected also in its presence in the large, putatively cholinergic cells of the striatum (see above). Its presence in these cells would indicate a potential association with at least the presynaptic side of cholinergic synapses. The absence of expression by the cells of the pars compacta of the substantia nigra suggests that it is not associated with at least the presynaptic side of dopaminergic synapses, as well. In a study on the brainstem of the rat (Benson et al., 1991b), we found that CAM II kinase- $\alpha$ mRNA was also absent from known populations of noradrenergic and serotoninergic cells, again implying a lack of association of the protein with the presynaptic side of monoaminergic synapses.

\section{Postsynaptic distribution}

CAM II kinase- $\alpha$ is particularly enriched in postsynaptic densities (Kennedy et al., 1983; Kelly et al., 1984; Ouimet et al., 1984a), and cell fractionation studies that preferentially isolate the postsynaptic densities of asymmetric synapses (Kelly and Cotman, 1981) have shown that the protein is a major constituent of these densities (Kelly and Montgomery, 1982; Kelly and Vernon, 1985). It is not clear from published electron micrographs whether it is also associated with the other of the two principal forms of forebrain synapse, the symmetric synapses (see Peters et al., 1976). The symmetric morphology is associated with GABA synapses (Ribak, 1978; Hendry ct al., 1983), and the asymmetric, with known excitatory synapses.

In the hippocampus and cerebral cortex (Burgin et al., 1990; Benson et al., 1991a), CAM II kinase- $\alpha$ mRNA appears to be enriched in the apical and basal dendrites of pyramidal neurons and has been putatively associated with the free ribosomes found at the necks of dendritic spines (Steward, 1983), each of which receives an excitatory synapse whose morphology is asymmetric (Jones and Powell, 1969; Peters and Kaiserman-Abramof, 1969). It is possible, therefore, that the mRNA may actually be translated at the dendritic spine neck close to the related synapse. By contrast, the mRNA for the $\beta$-subunit appears largely confined to the somata of pyramidal neurons (Burgin et al., 1990). After the cerebral cortex and hippocampus, the striatum displays the greatest neuropil-like distribution of CAM II kinase- $\alpha$ mRNA, and the striatum, as mentioned above, contains numerous spiny neurons, onc typc at least of which projects to the substantia nigra. CAM II kinase- $\alpha$ mRNA may therefore be particularly associated with spine synapses in the striatum. Asymmetrical synapses on dendritic spines are made by corticostriatal axons (Kemp and Powell, 1971b), and there is evidence that the transmitter involved is an excitatory amino acid (Fonnum, 1984; Herrling, 1985). An excitatory amino acid transmitter is also involved in cerlain forms of long-term potentiation mediated via commissural fibers that end in hippocampal spine synapses (see Zalutsky and Nicoll, 1990). In the thalamus, though spines are not present, the asymmetric synapses made by somatosensory afferents on relay neurons appear to release excitatory amino acids (Salt, 1986). Thus, postsynaptic CAM II kinase- $\alpha$ may be associated with excitatory amino acid synapses.

CAM II kinase- $\alpha$ is involved in the induction of long-term potentiation at hippocampal synapses (Malcnka ct al., 1989; Malinow et al., 1989). It also appears to play a role in mediating certain forms of short-term synaptic plasticity in invertebrate preparations (Neary et al., 1981; Willmund et al., 1986; Lisman and Goldring, 1988). The exact mechanisms that underlie these phenomena are still not completely clear. However, transcriptionally dependent increases in protein phosphorylation occur during transmitter-induced long-term synaptic facilitation in Aplysia (Sweatt and Kandel, 1989), and CAM II kinase, when injected into motor cortex neurons of cats and followed by depolarization of the neurons, leads to an increase in input resistance (Woody et al., 1984). This could be a basis for adaptive behavior of the neurons. The effects may relate to the capacity of the kinase for autophosphorylation, and thus for independent activity subsequent to an initial calcium transient (Miller and Kennedy, 1986), and also to its capacity to phosphorylate a 
number of substrates in the postsynaptic cell. These include certain ubiquitously distributed phosphoproteins such as synapsin I, structural proteins such as MAP2, and enzymes involved in transmitter synthesis such as tyrosine hydroxylase and tryptophan hydroxylase (Bennett et al., 1983; Yamauchi and Fujisawa, 1983; Schulman, 1984; Vulliet et al., 1984). It is possible that the differential distribution of protein kinases such as CAM II kinase- $\alpha$ and of their substrates may provide a basis for differential long-term effects at different types of synapse.

The presence or absence of a particular substrate could ensure a specificity of action of a kinase that is capable of acting on a wide variety of substrates. In this context, it is interesting to note that the cAMP-regulated phosphoprotein ARRP-21, which may function as a third messenger mediating the effects of dopamine and vasoactive intestinal polypeptide, is, like CAM II kinase- $\alpha$, also found on the presynaptic but not the postsynaptic side of certain synapses. These include the synapses in the striatopallidal, striatonigral, and certain other forebrain pathways in the rat (Ouimet et al., 1989).

\section{Conclusion}

Overall, the present results reveal that neuronal identity in the higher levels of the CNS can be revealed by differential gene expression for a major second-messenger-related protein whose distribution has previously been considered to be rather general. Essentially three populations of neurons have been revealed: those that express CAM II kinase- $\alpha$ only, those that express GAD only, and those that express neither. Determining the functional significance of these distinctions will be a major task for future investigations.

\section{Appendix}

$\mathrm{AD}$ anterodorsal nucleus of thalamus

AHA antcrior hypothalamic area

Am amygdala

AM anteromedial nucleus of thalamus

Arc arcuate nucleus of hypothalamus

AV anteroventral nucleus of thalamus

BNM basal nucleus of Meynert

$\mathrm{CeM} \quad$ central medial nucleus of thalamus

CG central gray

$\mathrm{Cl} \quad$ claustrum

CL central lateral nucleus of thalamus

$\mathrm{CM} \quad$ centre médian nucleus of thalamus

CN caudate nucleus

Co cerebral cortex

$\mathrm{CP} \quad$ cerebral peduncle

DMH dorsal medial hypothalamic nucleus

Em median eminence

F fornix

FF fields of Forel

Fil filiform nucleus

GPe globus pallidus, external division

GPi globus pallidus, intermediate division

$\mathrm{Hl}, \mathrm{Hm}$ nuclei of habenula

HP, HPT habenulopeduncular tract

IC internal capsule

IP interpeduncular nuclei

Is interstitial nucleus of Cajal

L limitans nucleus of thalamus

LD lateral dorsal nucleus of thalamus

LG dorsal lateral geniculate nucleus

LHA lateral hypothalamic area

LM medial lemniscus

LMN lateral mamillary nucleus

LP lateral posterior nucleus of thalamus

MC magnocellular medial geniculate nucleus
MDl mediodorsal nucleus of thalamus, lateral division

MDm mediodorsal nucleus of thalamus, medial division

MG medial geniculate nuclei

MMN medial mamillary nucleus

MTT mamillothalamic tract

MV medial ventral nucleus of thalamus

OT optic tract

Pc paracentral nucleus

Pf parafascicular nucleus of thalamus

PHA posterior hypothalamic area

$\mathrm{Pla} \quad$ anterior pulvinar nucleus

$\mathrm{Pli} \quad$ inferior pulvinar nucleus

Pll lateral pulvinar nucleus

PIm medial pulvinar nucleus

Po posterior nucleus of thalamus

$\mathrm{Pp} \quad$ peripeduncular nucleus

Prg pregeniculate nucleus

$\mathrm{Pt} \quad$ parataenial nucleus

PT pretectal nuclei

$\mathrm{Pu} \quad$ putamen

Pv paraventricular neuclei of thalamus

PV paraventricular nucleus of hypothalamus

$R \quad$ reticular nucleus

$\mathrm{Rh} \quad$ rhomboid nucleus

RNm red nucleus, magnocellular division

RNp red nucleus, parvocellular division

$S \quad S$ layers of dorsal lateral geniculate nucleus

$\mathrm{Sb} \quad$ subthalamic nucleus

SG suprageniculate nucleus

SI substantia innominata

SM stria medullaris

SNC substantia nigra, pars compacta

SNR, SNr substantia nigra, pars reticulata

ST stria terminalis

TMN tuberomamillary nucleus

Tu tuberal nuclei

VA ventral anterior nucleus of thalamus

VAmc ventral anterior nucleus of thalamus, magnocellular division

VLa anterior ventral lateral nucleus of thalamus

VLp posterior ventral lateral nucleus of thalamus

VM ventral medial nucleus of thalamus

$\mathrm{VMb} \quad$ basal ventral medial nucleus of thalamus

VMH ventral medial hypothalamic nucleus

VPI ventral posterior inferior nucleus of thalamus

VPL ventral posterior lateral nucleus of thalamus

VPM ventral posterior medial nucleus of thalamus

ZI zona incerta

III oculomotor nucleus or nerve

\section{References}

Aoki C, Pickel VM (1989) Neuropeptide Y in the cerebral cortex and the caudate-putamen nuclei: ultrastructural basis for interactions with GABAergic and non-GABAergic neurons. J Neurosci 9:4333-4354.

Araki M, McGeer PL, McGeer EG (1985) Striatonigral and pallidonigral pathways studied by a combination of retrograde horseradish peroxidase tracing and a pharmacohistochemical method for gammaaminobutyric acid transaminase. Brain Res 331:17-24.

Arimatsu Y, Naegele JR, Barnstable CJ (1987) Molecular markers of neuronal subpopulations in layers 4,5 and 6 of cat primary visual cortex. J Neurosci 7:1250-1263.

Aronin N, DiFiglia M, Graveland GA, Schwartz WJ, Wu J-Y (1984) Localization of immunoreactive enkephalins in GABA synthesizing neurons of the rat neostriatum. Brain Res 300:376-380.

Beal MF, Kowall NW, Ellison DW, Mazurek MF, Swartz KF, Martin JB (1986) Replication of the neurochemical characteristics of Huntington's disease by quinolinic acid. Nature 321:168-171.

Beckstead RM, Kersey KS (1985) Immunohistochemical demonstration of differential substance P-, Met-enkephalin-, and glutamic acid decarboxylase-containing cell body and axon distributions in the corpus striatum of the cat. J Comp Neurol 232:481-498.

Bennett MK, Erondu NE, Kennedy MB (1983) Purification and characterization of a calmodulin-dependent protein kinase that is highly concentrated in brain. J Biol Chem 258:12735-12744. 
Benson DL, Isackson PJ, Hendry SHC, Jones EG (1989) Expression of glutamic acid decarboxylase mRNA in normal and monocularly deprived cat visual cortex. Mol Brain Res 5:279-287.

Benson DL, Isackson PJ, Gall CM, Jones EG (1991a) Differential effects of monocular deprivation on glutamic acid decarboxylase and type II calcium-calmodulin-dependent protein kinase gene expression in adult monkcy visual cortex. J Neurosci 11:31-47.

Benson DL, Isackson PJ, Jones EG (1991b) Differential gene expression for glutamic acid decarboxylase and type II calcium/calmodulin dependent protein kinase alpha in the brain of the rat. Neuroscience, in press.

Bolam JP, Somogyi P, Takagi H, Fodor I, Smith AD (1983) Localization of substance P-like immunoreactivity in neurons and nerve terminals in the neostriatum of the rat: a correlated light and electron microscopic study. J Neurocytol 12:325-344.

Bolam JP, Wainer BH, Smith AD (1984) Characterization of cholinergic neurons in the rat neostriatum. A combination of choline acetyltransferase immunocytochemistry, Golgi-impregnation and electron microscopy. Neuroscience 12:711-718.

Bolam JP, Powell JF, Wu JY, Smith AD (1985) Glutamate decarboxylase-immunoreactive structures in the rat ncostriatum. A correlated light and electron microscopic study including a combination of Golgi-impregnation with immunocytochemistry. J Comp Neurol 237:1-20.

Brownstein MJ, Morz EA, Tappaz ML, Leeman SE (1977) On the origin of substance $P$ and glutamic acid decarboxylase (GAD) in the substantia nigra. Brain Res 135:315-323.

Bulleit RF, Bennett MK, Malloy SS, Hurley JB, Kennedy MB (1988) Conserved and variable regions in the subunits of brain type II $\mathrm{Ca}^{2+} /$ calmodulin-dependent protein kinase. Neuron 1:63-72.

Burgin KE, Waxham MN, Rickling S, Westgate SA, Mobley WC, Kelly PI (1990) In situ hybridization histochemistry of $\mathrm{Ca}^{2+} /$ calmodulindependent protein kinase in developing rat brain. J Neurosci 10:17881798.

Cajal S Ramón y (1900) Estudios sobrc la corteza cercbral humana. III. Corteza acústica. Trab Inst Cajal Invest Biol 5:129-183.

Carpenter MB, Peter P (1972) Nigrostriatal and nigrothalamic fibers in the rhesus monkey. J Comp Neurol 144:93-116.

Carpenter MB, Nakano K, Kim R (1975) Nigrothalamic projections in the monkey demonstrated by autoradiographic technics. J Comp Neurol 165:401-418.

Celio MR, Heizmann CW (1981) Calcium-binding protein parvalbumin as a neuronal marker. Nature 293:300-312.

Chang HT, Wilson CJ, Kitai ST (1982) A Golgi study of rat neostriatal neurons: light microscopic analysis. J Comp Neurol 208:107-126.

Chesselet M-F, Graybiel AM (1986) Striatal neurons expressing somatostatin-like immunoreactivity: evidence for a peptidergic interneuronal system in the cat. Neuroscience 17:547-571.

Chesselet M-F, Robbins E (1989) Characterization of striatal neurons expressing high levels of glutamic acid decarboxylase messenger RNA. Brain Res 492:237-244.

Chesselet M-F, Weiss L, Wuenschell C, Tobin AJ, Affolter H-U (1987) Comparative distribution of $m$ RNAs for glutamic acid decarboxylase, tyrosine hydroxylase and tachykinins in the basal ganglia: an in situ hybridization study in the rodent brain. J Comp Neurol 262:125140.

Cowan RL, Wilson CJ, Emson PC (1987) Parvalbumin is present in GABA containing interneurons of the rat neostriatum. Soc Neurosci Abstr 13:1573.

Dc Camilli P, Cameron R, Greengard P (1983) Synapsin I (protein I), a nerve terminal-specific phosphoprotein. I. Its general distribution in synapses of the central and peripheral nervous system demonstrated by immunofluorescence in frozen and plastic sections. J Cell Biol 96:1337-1354.

Del Fiacco M, Paxinos G, Cuello AC (1982) Neostriatal enkephalin immunoreactive neurons project to the globus pallidus. Brain Res 231:1-17.

Desbau M, Gauchy C, Kemel MC, Besson MJ, Glowinski J (1989) Three-dimensional organization of the striosomal compartment and patchy distribution of striatonigral projections in the matrix of the cat caudate nucleus. Neuroscience 29:551-566.

DeVito JL, Anderson ME (1982) An autoradiographic study of efferent connections of the globus pallidus in Macaca mulatta. Exp Brain Res 46:107-117.

DiChiara G, Porceddu ML, Morelli M, Mulas ML, Gessa GL (1979) Evidence for a GABAergic projection from the substantia nigra to the ventromedial thalamus and to the superior colliculus of the rat Brain Res 176:273-284.

DiFiglia M, Pasik P, Pasik T (1976) A Golgi study of neuronal types in the neostriatum of monkeys. Brain Res 114:245-256.

DiFiglia M, Aronin N, Martin JB (1982) Light and electron microscopic localization of immunoreactive Leu-enkephalin in the monkey basal ganglia. J Neurosci 2:303-320.

Elde R, Hökfelt T, Johansson O, Terenius L (1976) Immunohistochemical studies using antibodies to leucine-enkephalin: initial observations on the nervous system of the rat. Neuroscience 1:349-351.

Emmers R, Akert K (1963) A stereotaxic atlas of the brain of the squirrel monkey (Saimiri sciureus). Madison: University of Wisconsin.

Emson PC, ed (1983) Chemical neuroanatomy. New York: Raven.

Erondu NE, Kennedy MB (1985) Regional distribution of type II $\mathrm{Ca}^{2+}$ / calmodulin dependent protein kinase in rat brain. J Neurosci 5:32703277.

Faull RLM, Mehler WR (1978) The cells of origin of nigrotectal, nigrothalamic and nigrostriatal projections in the rat. Neuroscience 3:989-1002.

Finlay JCW, Maderdrut JL, Petrusz P (1981) The immunocytochemical localization of enkephalin in the central nervous system of the rat. J Comp Neurol 198:541-565.

Fitzpatrick D, Itoh K, Diamond IT (1983) The laminar organization of the lateral geniculate body and the striate cortex in the squirrel monkey (Saimiri sciureus). J Neurosci 3:673-702.

Fitzpatrick D, Penny GR, Schmechel DE (1984) Glutamic acid decarboxylase-immunoreactive neurons and terminals in the lateral geniculate nucleus of the cat. J Neurosci 4:1809-1829.

Fonnum F (1984) Glutamate: a neurotransmitter in mammalian brain. J Neurochem 42:1-11.

Fonnum F, Grofová I, Rinvik I, Storm-Mathison J, Walberg F (1974) Origin and distribution of glutamate decarboxylase in substantia nigra of cat. Brain Res 71:77-92.

Fonnum F, Gottesfeld Z, Grofová I (1978) Distribution of glutamate decarboxylase, choline acetyltransferase and aromatic amino acid decarboxylase in the basal ganglia of normal and operated rats. Evidence of striatopallidal, striatoentopeduncular and striatonigral GABAergic fibers. Brain Res 143:125-138.

Fox CA, Andrade AN, Hillman DE, Schwyn RC (1971) The spiny neurons in the primate striatum. A Golgi and electron microscopic study. J Hirnforsch 13:181-201.

Francois C. Percheron G, Yelnik J (1984) Localization of nigrostriatal, nigrothalamic and nigrotectal neurons in ventricular coordinates in macaques. Neuroscience 13:61-76.

Gall CM, Isackson PJ (1989) Limbic seizures increase neuronal production of messenger RNA for nerve growth factor. Science 245:758761.

Gerfen CR (1985) The neostriatal mosaic. I. Compartmental organization of projections from the striatum to the substantia nigra in the rat. J Comp Neurol 236:454-476.

Gerfen CR (1988) Synaptic organization of the striatum. J Electron Microsc Technol 10:265-281.

Gerfen CR, Young WS (1988) Distribution of striatonigral and striatopallidal peptidergic neurons in both patch and matrix compartments: an in situ hybridization histochemistry and fluorescent retrograde tracing study. Brain Res 460:161-167.

Gottesfeld Z, Massani VJ, Muth EA, Jacobowitz DM (1977) Stria medullaris: a possible pathway containing GABAergic afferents to the lateral habenula. Brain Res 130:184-189.

Gottesfeld Z, Brandon C, Wu J-Y (1981) Immunocytochemistry of glutamate decarboxylase in the deafferented habenula. Brain Res 208: 181-186.

Graybiel AM, Ragsdale CW Jr (1983) The striatum. In: Chemical neuroanatomy (Emson PC, ed), pp 427-504. New York: Raven.

Graybiel AM, Ragsdale CW Jr, Yoneika ES, Elde RP (1982) An immunohistochemical study of enkephalins and other neuropeptides in the striatum of the cat with evidence that the opiate peptides are arranged to form mosaic patterns in register with the striosomal compartments visible with acetylcholinesterase staining. Neuroscience 6: 377-398

Grofová I (1975) The identification of striatal and pallidal neurons projecting to the substantia nigra. An experimental study by means of retrograde axonal transport of horseradish peroxidase. Brain Res 91:286-291.

Haber S, Nauta WJH (1983) Ramifications of the globus pallidus in 
the rats as indicated by patterns of immunohistochemistry. Neuroscience 9:245-260.

Hendrickson AE, Ogren MP, Vaughn JE, Barber RP, Wu J-Y (1983) Light and electron microscopic immunocytochemical localization of glutamic acid decarboxylase in monkey geniculate complex: evidence for GABAergic neurons and synapses. J Neurosci 3:1245-1262.

Hendry SHC (1991) Delayed reduction in GABA immunoreactivity of dorsal lateral geniculate neurons following monocular deprivation in monkeys. Exp Brain Res, in press.

Hendry SHC, Houser CR, Jones EG, Vaughn JE (1983) Synaptic organization of immunocytochemically identified GABA neurons in the monkey sensory-motor cortex. J Neurocytol 12:639-660.

Hendry SHC, Jones EG, Hockfield S, McKay RDG (1988) Neuronal populations stained with the monoclonal antibody CAT-301 in the mammalian cerebral cortex and thalamus. J Neurosci 8:518-542.

Hendry SHC, Jones EG, Emson PC, Lawson DEM, Heizmann CW, Streit P (1989) Two classes of cortical GABA neurons defined by differential calcium binding protein immunoreactivities. Exp Brain Res 76:467-472.

Herkenham M (1979) The afferent and efferent connections of the ventromedial thalamic nucleus in the rat. J Comp Neurol 183:487518 .

Herrling PL (1985) Pharmacology of the corticocaudate excitatory postsynaptic potential in the cat: evidence for its mediation by quisqualate-or kainate-receptors. Neuroscience 14:417-426.

Hockfield S, McKay RDG (1983) A surface antigen expressed by a subset of neurons in the vertebrate central nervous system. Proc Natl Acad Sci USA 80:5758-5761.

Hökfelt T, Elde R, Johansson O, Terenius L, Stein L (1977) Distribution of enkephalin immunoreactive cell-bodies in the rat central nervous system. Neurosci Lett 5:25-31.

Hong JS, Yang H-Y'I, Costa E (1977) Projections of substance P containing neurons from neostriatum to substantia nigra. Brain Res 121:541-544.

Houser CR, Vaughn JE, Barber RP, Roberts E (1980) GABA neurons are the major cell type in the nucleus reticularis thalami. Brain Res 200:341-354.

Hubel DH, Wiesel TN (1977) Functional architecture of macaque monkey visual cortex. Proc R Soc Lond [Biol] 198:1-59.

Hunt CA, Pang DZ, Jones EG (1991) Numbers and proportions of GABA immunoreactive neurons in intralaminar and relay nuclei of the monkey thalamus. Neuroscience, in press.

Ilinsky IA, Kultas-Ilinsky K (1984) An autoradiographic study of topographical relationship between pallidal and cerebellar projections to the cat thalamus. Exp Brain Res 54:95-105.

llinsky IA, Jouandet ML, Goldman-Kakic PS (1985) Organization of the nigrothalamocortical system in the rhesus monkey. J Comp Neurol 236:315-330.

Jessell TM, Emson PC, Paxinos G, Cuello AC (1978) Topographic projections of substance $P$ and GABA pathways in the striato- and pallido-nigral system: a biochemical and immunohistochemical study. Brain Res 152:487-498.

Jimenez-Castellanos J, Graybiel AM (1989) Evidence that histochemically distinct zones of the primate substantia nigra pars compacta are related to patterned distribution of nigrostriatal projection neurons and striatonigral fibers. Exp Brain Res 74:227-238.

Jones EG (1985) The thalamus. New York: Plenum.

Jones EG, Hendry SHC (1989) Differential calcium binding protein immunoreactivity distinguishes classes of relay neurons in monkey thalamic nuclei. Eur J Neurosci 1:222-246.

Jones EG, Powell TPS (1969) Morphological variations in the dendritic spines of the neocortex. J Cell Sci 5:509-529.

Kanagawa I, Emson PC, Cuello AC (1977) Evidence for the existence of substance $\mathrm{P}$-containing fibers in the striato-nigral and pallido-nigral pathways in rat brain. Brain Res 119:447-453.

Kaufman DL, Houser CR, Tobin AJ (1989) Two forms of glutamic acid decarboxylase (GAD), with different $\mathrm{N}$-terminal sequences, have distinct intraneuronal distributions. Soc Neurosci $\Lambda$ bstr 15:487.

Kelly PT, Cotman C (1981) Developmental changes in morphology and molecular composition of isolated synaptic junctional structures. Brain Res 206:251-271.

Kelly PT, Montgomery PR (1982) Subcellular localization of the 52,000 molecular weight major postsynaptic density protein. Brain Res 223 : 265-286.

Kelly PT, Vernon P (1985) Changes in the subcellular distribution of calmodulin kinase II during brain development. Dev Brain Res 18 221-224.

Kelly PT, McGuinness TL, Greengard P (1984) Evidence that the major postsynaptic density protein is a component of a $\mathrm{Ca}^{2+} / \mathrm{cal}-$ modulin dependent protein kinase. Proc Natl Acad Sci USA 81:945949.

Kemp JM, Powell TPS (1971a) The structure of the caudate nucleus of the cat: light and electron microscopy. Philos Trans R Soc Lond [Biol] 262:383-401.

Kemp JM, Powell TPS (1971b) The site of termination of afferent fibres in the caudate nucleus. Philos Trans R Soc Lond [Biol] 262: 413-427.

Kennedy MB, Bennett MK, Erondu NE (1983) Biochemical and immunochemical evidence that the "major postsynaptic density protein" is a subunit of a calmodulin-dependent protein kinase. Proc Natl Acad Sci USA 80:7357-7361.

Kilpatrick IC, Starr MS, Fletcher A, James TA, McLeod NK (1980) Evidence for a GABAergic nigrothalamic pathway in the rat. I. Behavioral and biochemical studies. Exp Brain Res 40:45-54.

Kim R, Nakano K, Jayaraman A, Carpenter MB (1976) Projections of the globus pallidus and adjacent structures: an autoradiographic study in the monkey. J Comp Neurol 169:263-290.

Kita H, Chang HT, Kitai ST (1983) Pallidal inputs to subthalamus: intracellular analysis. Brain Res 264:255-265.

Kobayashi Y, Kaufman DL, Tobin AJ (1987) Glutamic acid decarboxylase cDNA: nucleotide sequence encoding an enzymatically active fusion protein. $\mathrm{J}$ Neurosci 7:2769-2772.

Kultas-Ilinsky K, Ilinsky IA, Young PA, Smith KR (1978) Nigrothalamic pathway in the cat demonstrated by autoradiography and electron microscopy. Exp Brain Res 38:125-135.

Kultas-Ilinsky K, Ilinsky I, Warton S, Smith KR (1983) Fine structure of nigral and pallidal afferents in the thalamus: an EM autoradiography study in the cat. J Comp Neurol 216:390-405.

Lin CR, Kapiloff MS, Durgerian S, Tatemoto K, Russo AF, Hansen P, Schulman H, Rosenfeld MG (1987) Molecular cloning of a brainspecific calcium/calmodulin-dependent protein kinase. Proc Natl Acad Sci IJSA 84:5962-5966.

Lisman JE, Goldring MA (1988) Feasibility of long-term storage of graded information by the $\mathrm{Ca}^{++} /$calmodulin-dependent protein kinase molecules of the postsynaptic density. Proc Natl Acad Sci USA 85: $5320-5324$

Livingstone MS, Hubel DH (1983) Thalamic inputs to cytochrome oxidase-rich regions in monkey visual cortex. Proc Natl Acad Sci USA 79:6098-6101.

Ljungdahl A, Hökfelt T, Nilsson G (1978) Distribution of substance P-like immunoreactivity in the central nervous system of the rat-I. Cell bodies and nerve terminals. Neuroscience 3:861-963.

Llinás R, McGuinness TL, Leonard CS, Sugimori M, Greengard P (1985) Intraterminal injection of synapsin I or calcium/calmodulindependent protein kinase II alters neurotransmitter release at the squid giant synapse. Proc Natl Acad Sci USA 82:3035-3039.

Malenka RC, Kauer JA, Perkel DJ, Mauk MD, Kelly PT, Nicoll RA, Waxham MN (1989) An essential role for postsynaptic calmodulin and protein kinase activity in long-term potentiation. Nature 340 554-557.

Malinow R, Schulman H, Tsien RW (1989) Inhibition of postsynaptic PKC or CaMKII blocks induction but not expression of LTP. Science 245:862-866.

McGuinness TL, Brady ST, Gruner JA, Sugimori M, Llinás R, Greengard P (1989) Phosphorylation-dependent inhibition by synapsin I of organelle movement in squid axoplasm. J Neurosci 9:4139-4149.

McLeod NK, James TA, Kilpatrick IC, Starr MS (1980) Evidence for GABAergic nigrothalamic pathway in the rat. II. Electrophysiological studies. Exp Brain Res 40:55-61.

Miller SG, Kennedy MB (1986) Regulation of brain type II $\mathrm{Ca}^{2+}$ calmodulin-dependent protein kinase by autophosphorylation: a $\mathrm{Ca}^{2+}$ triggered molecular switch. Cell 44:861-870.

Montero VM (1986) The interneuronal nature of GABAergic neurons in the lateral geniculate nucleus of the rhesus monkey: a combined HRP and GABA-immunocytochemical study. Exp Brain Res 64:615622.

Montero VM, Scott GL (1981) Synaptic terminals in the dorsal lateral geniculate nucleus from neurons of the thalamic reticular nucleus: a light and electron microscopic autoradiographic study. Neuroscience 6:2561-2577. 
Montero VM, Singer W (1985) Ultrastructural identification of somata and neural processes immunoreactive to antibodies against glutamic acid decarboxylase (GAD) in the dorsal lateral geniculate nucleus of the cat. Exp Brain Res 60:603-609.

Montero VM, Zempel J (1986) The proportion and size of GABAimmunoreactive neurons in the magnocellular and parvocellular layers of the lateral geniculate nucleus of the rhesus monkey. Exp Brain Res 62:215-223.

Mugnaini E, Oertel WH (1985) GABAergic neurons and terminals in the rat CNS. In: Handbook of chemical neuroanatomy, Vol 4, GABA and neuropeptides in the CNS (Bjorklund A, Hokfelt T, eds), pp 436508. New York: Raven.

Nagy JL, Carter DA, Lehman J, Fibiger HC (1978a) Evidence for a GABA-containing projection from the entopeduncular nucleus to the lateral habenula in the rat. Brain Res 145:360-364.

Nagy JL, Carter DA, Fibiger HC (1978b) Anterior striatal projections to the globus pallidus, entopeduncular nucleus and substantia nigra in the rat. The GABA connection. Brain Res 158:15-29.

Nauta WJH, Cuénod M (1982) Perikaryal cell labeling in the subthalamic nucleus following the injection of ${ }^{3} \mathrm{H}$-gamma-aminobutyric acid into the pallidal complex: an autoradiographic study in cat. Neuroscience 7:2725-2734.

Neary KT, Crow T, Alkon DL (1981) Change in a specific phosphoprotein band following associative learning. Nature 293:658-660.

Nestler EJ, Greengard P (1984) Protein phosphorylation in the nervous system. New York: Wiley.

Nestler EJ, Walaas SI, Greengard P (1984) Neuronal phosphoproteins: physiological and clinical implications. Science 225:1357-1364.

Oertel WH, Mugnaini E (1984) Immunocytochemical studies of GABAergic neurons in rat basal ganglia and their relations to other neuronal systems. Neurosci Lett 47:233-238.

Oertel WH, Schmechel DE, Brownstein MJ, Tappaz ML, Ransom DH, Kopin IJ (1981) Decrease of glutamic decarboxylase (GAD)-immunoreactive nerve terminals in the substantia nigra after kainic acid lesion of the striatum. J Histochem Cytochem 29:977-980.

Oertel WH, Graybiel AM, Mugnaini E, Elde RP, Schmechel DE, Kopin IJ (1983) Coexistence of glutamic acid decarboxylase and somatostatin-like immunoreactivity in neurons of the feline nucleus reticularis thalami. J Neurosci 3:1322-1332.

Ohara PT, Sefton AJ, Lieberman AJ (1980) Mode of termination of afferents from the thalamic reticular nucleus in the dorsal lateral geniculate nucleus of the rat. Brain Res 197:503-506.

Ouimet CC, McGuinness TL, Greengard P (1984a) Immunocytochemical localization of calcium-calmodulin dependent protein kinase II in rat brain. Proc Natl Acad Sci USA 81:5604-5608.

Ouimet CC, Miller PE, Hemmings HC Jr, Walaas SI, Greengard P (1984b) DARPP-32, a dopamine- and adenosine $3^{\prime}: 5^{\prime}$-monophosphate-regulated phosphoprotein enriched in dopamine-innervated brain regions. III. Immunocytochemical localization. J Neurosci 4: 111-124.

Ouimet CC, Hemmings HC Jr, Greengard P (1989) ARRP-21, a cyclic AMP-regulated phosphoprotein enriched in dopamine-innervated brain regions. II. Immunocytochemical localization in rat brain. J Neurosci 9:865-875.

Penney JB, Young AB (1981) GABA as the pallidothalamic neurotransmitter: implications for basal ganglia function. Brain Res 207 195-199.

Penney JB Jr, Young AB (1983) Speculations on the functional anatomy of basal ganglia disorders. Annu Rev Neurosci 6:73-94.

Penny GR, Fitzpatrick D, Schmechel DE, Diamond IT (1983) Glutamic acid decarboxylase immunoreactive neurons and horseradish peroxidase labeled projection neurons in the ventral posterior nucleus of the cat and Galago senegalensis. J Neurosci 3:1868-1887.

Penny GR, Afsharpour S, Kitai ST (1986) The glutamic acid decarboxylase-leucine-enkephalin-, methionine-enkephalin- and substance P-immunoreactive neurons in the neostriatum of the rat and cat: evidence for partial population overlap. Neuroscience 17:10111045.

Perez de la Mora M, Possani LD, Tapia R, Teran L, Palacios R, Fuxe K, Hökfelt T, Ljungdahl A (1981) Demonstration of central gammaaminobutyrate-containing nerve terminals by means of antibodies against glutamate decarboxylase. Neuroscience 6:875-895.

Peters A, Kaiserman-Abramof IR (1969) The small pyramidal neuron of the rat cerebral cortex. The synapses upon dendritic spines. $Z$ Zellforsch 100:487-506.
Peters A, Palay SL, Webster HD (1976) The fine structure of the nervous system: the neurons and supporting cells, pp 66-89. Philadelphia: Saunders.

Phelps PE, Houser CR, Vaughn JE (1985) Immunocytochemical localization of choline acetyltransferase within the rat neostriatum: a correlated light and electron microscopic study of cholinergic neurons and synapses. J Comp Neurol 238:286-307.

Pickel VM, Sumal KK, Beckley SC, Miller RJ, Reis DJ (1980) Immunocytochemical localization of enkephalin in the neostriatum of rat brain: a light and electron microscopic study. J Comp Neurol 189: 721-740.

Preston RJ, Bishop GA, Kitai ST (1980) Medium spiny neurons projection from the rat striatum: an intracellular horseradish peroxidase study. Brain Res 185:253-263.

Ribak CE (1978) Aspinous and sparsely-spinous stellate neurons contain glutamic acid decarboxylase in the visual cortex of rats. J Neurocytol 7:461-476.

Ribak CE, Vaughn JE, Roberts E (1979) The GABA neurons and their axon terminals in rat corpus striatum as demonstrated by GAD immunocytochemistry. J Comp Neurol 187:261-284

Ribak CE, Vaughn JE, Roberts E (1980) GABAergic nerve terminals decrease in the substantia nigra following hemitransections of the striatonigral and pallidonigral pathways. Brain Res 192:413-420.

Ribak CE, Vaughn JE, Barber RP (1981) Immunocytochemical localization of GABAergic neurones at the electron microscopical level. Histochem J 13:555-582.

Roberts E, Chase TN, Tower DB, eds (1976) GABA in nervous system function. New York: Raven.

Salt TE (1986) Mediation of thalamic sensory input by both NMDA receptors and non-NMDA receptors. Nature 322:263-265.

Sar M, Stumpf WE, Miller RJ, Chang KJ, Cuatrecasas P (1978) Immunohistochemical localization of enkephalin in rat brain and spinal cord. J Comp Neurol 182:17-38.

Schulman H (1984) Phosphorylation of microtubule-associated proteins by a $\mathrm{Ca}^{2+} /$ calmodulin-dependent protein kinase. J Cell Biol 99 11-19.

Seroogy K, Schalling M, Brene S, Dagerlind A, Chai SY, Hökfelt T, Persson H, Brownstein M, Huan R, Dixon J, Filer D, Schlessinger D, Goldstein M (1989) Cholecystokinin and tyrosine hydroxylase messenger RNAs in neurons of rat mesencephalon: peptide/monoamine coexistence studies using in situ hybridization combined with immunocytochemistry. Exp Brain Res 74:149-162.

Smith Y, Bolam JP (1989) Neurons of the substantia nigra reticulata receive a dense GABA-containing input from the globus pallidus in the rat. Brain Res 493:160-167.

Smith Y, Parent A (1986a) Differential connections of caudate nucleus and putamen in the squirrel monkey (Saimiri sciureus). Neuroscience 18:347-371.

Smith Y, Parent A (1986b) Neuropeptide Y-immunoreactive neurons in the striatum of cat and monkey: morphological characteristics, intrinsic organization and colocalization with somatostatin. Brain Res 241:241-252.

Smith Y, Parent A (1988) Neurons of the subthalamic nucleus in primates display glutamate but not GABA immunoreactivity. Brain Res 453:353-356.

Smith Y, Parent A, Seguela P, Descarries L (1987a) Distribution of GABA immunoreactive neurons in the basal ganglia of the squirrel monkey (Saimiri sciureus). J Comp Neurol 259:50-64.

Smith Y, Parent A, Seguela P (1987b) Distribution of GABA immunoreactive neurons in the thalamus of the squirrel monkey (Saimiri sciureus). Neuroscience 22:579-591.

Smith Y, Bolam JP, von Krosigk M (1990) Topographical and synaptic organization of the GABA-containing pallidosubthalamic projection in the rat. Eur J Neurosci 2:500-511.

Somogyi P, Smith AD (1979) Projection of neostriatal spiny neurons to the substantia nigra. Application of a combined Golgi-stained and horseradish peroxidase transport procedure at both the light and electron microscopic levels. Brain Res 178:3-15.

Somogyi P, Bolam JP, Smith AD (1985) Monosynaptic input and local axon collaterals of identified strionigral neurons. A light and electron microscopic study using the Golgi-peroxidase transport-degeneration procedure. J Comp Neurol 195:567-584.

Spreafico R, Schmechel DE, Ellis LC, Rustioni A (1983) Cortical relay neurons and interneurons in the $\mathrm{N}$. ventralis posterolateralis of cats: a horseradish peroxidase, electron microscopic, Golgi and immu- 
nocytochemical study. Neuroscience 9:491-509.

Starr M, Kilpatrick IC (1981) Distribution of gamma-aminobutyrate in the rat thalamus: specific decreases in thalamic gamma-aminobutyrate following lesion or electrical stimulation of the substantia nigra. Neuroscience 6:1095-1104.

Steward O (1983) Alterations in polyribosomes associated with dendritic spines during reinnervation of the dentate gyrus of the adult rat. J Neurosci 3:177-188.

Swanson LW (1987) The hypothalamus. In: Handbook of chemical neuroanatomy, Vol 5; Integrated systems of the CNS, Pt I, Hypothalamus, hippocampus, amygdala, retina (Björklund A, Hökfelt $T$, Swanson LW, eds), pp 1-124. Amsterdam: Elsevier.

Sweatt JD, Kandel ER (1989) Persistent and transcriptionally-dependent increase in protein phosphorylation in long-term facilitation of Aplysia sensory neurons. Nature 339:51-54.

Takagi H, Somogyi P, Somogyi J, Smith AD (1983) Fine structural studies on a type of somatostatin-immunoreactive neuron and its synaptic connections in the rat neostriatum: a correlated light and electron microscopic study. J Comp Neurol 214:1-16.

Tappaz ML, Wassef M, Oertel WH, Paut L, Pujol JF (1983) Light and electron microscopic immunocytochemistry of glutamic acid decarboxylase (GAD) in the basal hypothalamus: morphological evidence for neuroendocrine gamma aminobutyric acid (GABA). Neuroscience 9:271-287.

Ueki A (1983) The mode of nigrothalamic transmission investigated with intracellular recording in the cat. Exp Brain Res 49:116-124.

Uno M, Ozawa N, Yoshida M (1978) The mode of pallido-thalamic transmission investigated with intracellular recording from cat thalamus. Brain Res 33:493-507.

Van den Pol AN (1986) Tyrosine hydroxylase immunoreactive neurons throughout the hypothalamus receive glutamate decarboxylase immunoreactive synapses: a double preembedding immunocytochemical study with particulate silver and HRP. J Neurosci 6:877891.

Vincent SR, Johansson O (1983) Striatal neurons containing both somatostatin and avian pancreatic polypeptide (APP)-like immunoreactivities and NADPH-diaphorase activity: a light and electron microscopic study. J Comp Neurol 217:265-270.

Vincent SR, Hökfelt T, Christensson I, Terenius L (1982a) Immunohistochemical evidence for a dynorphin immunoreactive striatonigral pathway. Eur J Pharmacol 85:251-252.

Vincent SR, Hökfelt T, Wu J-Y (1982b) GABA neuron systems in hypothalamus and pituitary gland. Neuroendocrinology 34:117-125.

Vincent SR, Skirboll L, Hökfelt T, Johansson O, Lundberg JM, Elde RP, Terenius L, Kimmel J (1982c) Coexistence of somatostatinand avian pancreatic polypeptide (APP)-like immunoreactivity in some forebrain neurons. Neuroscience 7:439-446.

Vincent SR, Johansson O, Hökfelt T, Skirboll L, Elde RP, Terenius L, Kimmel J, Goldstein M (1983) NADPH-diaphorase: a selective histochemical marker for striatal neurons containing both somatostatin- and avian pancreatic polypeptide-like immunoreactivities. J Comp Neurol 217:252-263.

Vulliet PR, Woodgett JR, Cohen P (1984) Phosphorylation of tyrosine hydroxylase by calmodulin-dependent multiprotein kinase. J Biol Chem 259:13680-13683.

Wada E, Wada K, Boulter J, Deneris E, Heinemann S, Patrick J, Swanson LW (1989) Distribution of alpha2, alpha3, alpha4 and beta2 neuronal nicotinic receptor subunit mRNAs in the central nervous system: a hybridization histochemical study in the rat. J Comp Neurol 284:314-335.

Walaas I, Fonnum F (1980) Biochemical evidence for gamma-aminobutyrate containing fibers from the nucleus accumbens to the substantia nigra and ventral tegmental area in the rat. Neuroscience 5: 63-72.

Walaas I, Browning MD, Greengard P (1988) Synapsin Ia, synapsin $\mathrm{Ib}$, protein IIIa and protein IIIb, four related synaptic vesicle-associated phosphoproteins, share regional and cellular localization in rat brain. J Neurochem 51:1214-1220.

Weiss LT, Chesselet M-F (1989) Regional distribution and regulation of preprosomatostatin messenger RNA in the striatum as revealed by in situ hybridization histochemistry. Mol Brain Res 5:121-130.

Willmund R, Mitschulat H, Schneider K (1986) Longlasting modulation of $\mathrm{Ca}^{2+}$-stimulated autophosphorylation and subcellular distribution of the $\mathrm{Ca}^{2+} /$ calmodulin-dependent protein kinase in the brain of Drosophila. Proc Natl Acad Sci USA 83:9789-9793.

Wilson CJ, Groves PM (1981) Spontaneous firing patterns of identified spiny neurons in the rat neostriatum. Brain Res 220:67-80.

Woody CD, Alkon DL, Hay B (1984) Depolarization-induced effects of $\mathrm{Ca}^{2+}$-calmodulin-dependent protein kinase injection, in vivo, in single neurons of cat motor cortex. Brain Res 321:192-197.

Worley PF, Baraban JM, DeSouza EB, Snyder SH (1986a) Mapping second messenger systems in the brain: differential localizations of adenylate cyclase and protein kinase C. Proc Natl Acad Sci USA 83: 4053-4057.

Worley PF, Baraban JM, Snyder SH (1986b) Heterogeneous localization of protein kinase $\mathrm{C}$ in rat brain: autoradiographic analysis of phorbol ester receptor binding. J Neurosci 6:199-207.

Wuenschell C, Fisher RS, Kaufman DL, Tobin AJ (1986) In situ hybridization to localize mRNA encoding the neurotransmitter synthetic enzyme glutamic acid decarboxylase (GAD) in the mouse cerebellum. Proc Natl Acad Sci USA 83:6193-6197.

Yamauchi T, Fujisawa H (1983) Purification and characterization of the brain calmodulin-dependent protein kinase (kinase II) which is involved in the activation of tryptophan-5-monooxygenase. Eur $\mathrm{J}$ Biochem 132:15-21.

Yen C-T, Conley M, Hendry SHC, Jones EG (1985) The morphology of physiologically identified GABAergic neurons in the somatic sensory part of the thalamic reticular nucleus in the cat. J Neurosci 5: 2254-2268.

Young WS III, Bonner TI, Brann MR (1986) Mesencephalic dopaminergic neurons regulate the expression of neuropeptide mRNAs in the rat forebrain. Proc Natl Acad Sci USA 83:9827-9831.

Zalutsky RA, Nicoll RA (1990) Comparison of two forms of longterm potentiation in single hippocampal neurons. Science 248:16191624. 